
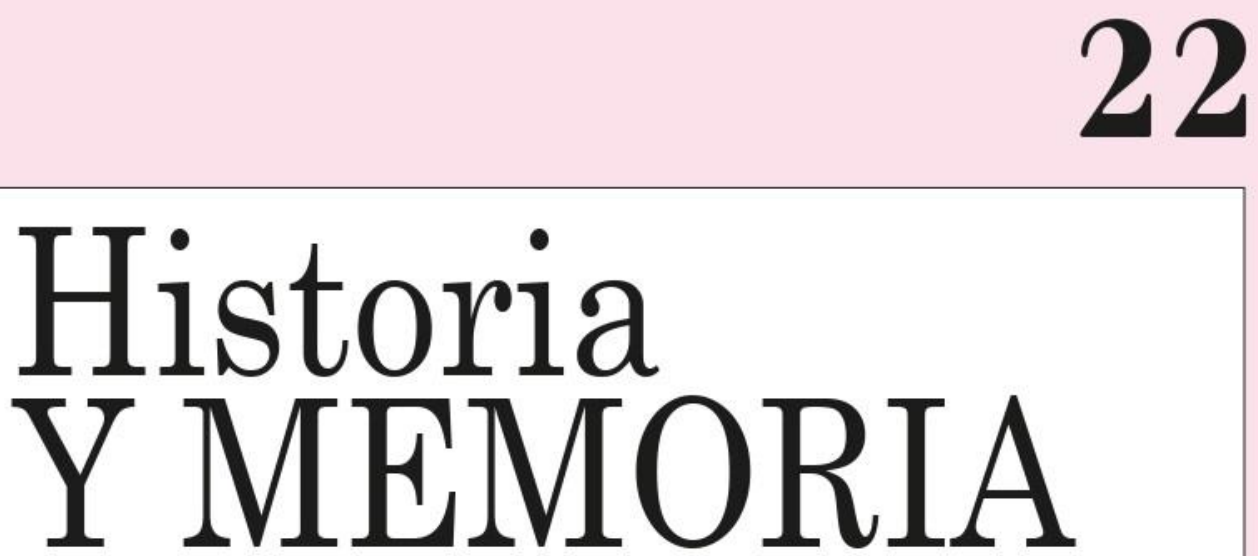

ISSN: 2027-5137

Enero - Junio, Año 2021 - Tunja, Colombia

Lugares de resistencia y memoria: residir y resistir

https:/doi.org/10.19053/20275137.n22.2021.9875

Jordi Guixé Lillian Carominas

Páginas 199-244

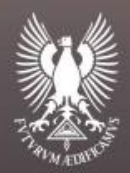




\title{
Lugares de resistencia y memoria: residir y resistir*
}

\author{
Jordi Guixé Corominas ${ }^{1}$ \\ Universidad de Barcelona - España
}

Recepción: 05/08/2019

Evaluación: 02/09/2019

Aprobación: 11/08/2020

Artículo de Investigación e Innovación

https:/doi.org/10.19053/20275137.n22.2021.9875

\section{Resumen}

El texto reflexiona sobre tres ejes claves la necesidad de considerar la memoria y sus espacios físicos y simbólicos como patrimonio colectivo en nuestros espacios de residencia; la necesidad y reto de transmitir y resignificar estos lugares como lugares de resistencia y como patrimonio transformador de valores actuales y contemporáneos; y la voluntad más actual de hacerlo de forma transnacional, comparada y en red. De ahí que el texto aborda una parte más reflexiva conceptual y teórica y otra parte habla de casos estudiados a modo de ejemplo sobre los debates y conflictos actuales que pueden ser modelos de trabajo y análisis. Conceptos como

\footnotetext{
* Este artículo se deriva del programa Education, Audiovisual and Culture Executive Agency, de la Comisión Europea, Specific decision grant, number 2018-0486-01-01. En colaboración también con el proyecto de investigación: HAR2017-84322-P y de título: Arte público y memoria. Desarrollos para el programa de intervención en la red de espacios de represión Franquista en Barcelona, Facultad de Bellas Artes de la Universidad de Barcelona.

1 Historiadora, directora del Observatorio Europeo de Memorias de la Fundación Solidaridad de la Universidad de Barcelona, profesora asociada de la Facultad de Bellas Artes sobre memoria y espacio público. Últimas Publicaciones: Jordi Guixé, dir., Observing Memories. Magazine of the European Observatory on Memories, $n^{\circ} 3$ (2019), https://europeanmemories.net/magazine/; Jordi Guixé, Jesús Alonso Carballés y Ricard Conesa, eds., Diez años de leyes y políticas de memòria (2007-2017) (Madrid: Los libros de la Catarata, 2019); Jordi Guixé, dir., Past and Power: Public Policies on Memory. Debates, from Global to Local (Barcelona: Edicions de la Universitat de Barcelona, 2016).凶jordiguixe@ub.edu (ㄱ https://orcid.org/0000-0003-3060-764X.
} 
la memoria múltiple, las memorias nostálgicas, resistentes, incómodas e incluso conflictivas son tratados como conceptos, pero el autor los intenta vincular a casos prácticos a través de la interpretación, transmisión cultural y turística de la memoria. Metodologicamente el texto combina la reflexión teórica con los casos prácticos de análisis concretos de espacios de memoria.

Palabras clave: memoria y resistencia, políticas públicas de memoria, lugares de memoria, memoria y turismo, memoria transnacional, patrimonio colectivo, memoria participativa.

\title{
Places of resistance and memory: reside and resist
}

\begin{abstract}
The text reflects upon three key axes: the need to consider memory and its physical and symbolic spaces as collective patrimony in our places of residence; the challenge of transmitting and giving new meaning to those spaces as places of resistance and as a patrimony that transforms current and contemporary values; and the most current willingness to carry this out in a way that is transnational, comparative and networked. From there the text addresses a more reflective, conceptual and theoretical element, and another which speaks of the cases studied by way of example of the debates and current conflicts that can be work and analysis models. Concepts such as multiple memory, nostalgic, resistant, uncomfortable, and even conflictive memories are dealt with as concepts, but the author attempts to link them to practical cases through interpretation, cultural and touristic transmission of memory. Methodologically, the text combines theoretical reflection with the practical cases of concrete analysis of spaces of memory.
\end{abstract}

Key words: memory and resistance, public policies of memory, spaces of memory, memory and tourism, transnational memory, collective patrimony, participative memory. 


\section{Lieux de résistance et de mémoire: vivre et résister}

\section{Résumé}

Cet article propose une réflexion autour de trois axes de travail: la nécessité de considérer la mémoire et ses espaces physiques et symboliques comme patrimoine collectif dans nos espaces domestiques; le besoin de transmettre et de ré-signifier ces lieux en tant que lieux de résistance et comme patrimoine transformateur de valeurs actuelles et contemporains; la volonté que l'on voit à présent de faire cela de manière transnationale, comparée et en réseaux. C'est bien pourquoi ce texte comporte une partie réflexive, conceptuelle et théorique et une autre partie qui traite de cas illustrant les débats et les conflits actuels qui peuvent devenir des modèles de travail et d'analyse. Quelques concepts, tels que la mémoire multiple, les mémoires nostalgiques, résistantes, inconfortables et même conflictuelles, sont traités ici en liaison d'avec des cas pratiques concernant l'interprétation, la transmission culturelle et la promotion touristique de la mémoire. En termes de méthodologie, ce texte mélange la réflexion théorique avec l'analyse de cas concrets d'espaces de mémoire.

Mots-clés: mémoire et résistance, politiques publiques de mémoire, lieux de mémoire, mémoire et tourisme, mémoire transnationale, patrimoine collectif, mémoire participative.

\section{Introducción}

El presente texto es un compendio de planteamientos alrededor de espacios y lugares de memoria que se activan en dos formas: una es la participación social y cultural y el trabajo ciudadano de memoria, y, en segundo lugar, los modelos comparativos transnacionales. Como autor planteo el texto como un ensayo teórico y práctico de cómo y dónde activar estas memorias, mientras pretendo mostrar al lector reflexiones sobre lugares existentes que puedan plantear memorias resistentes o resistencias memoriales a través de lo que se considera patrimonio memorial colectivo. En un primer 
apartado se plantean los conceptos a debatir sobre lugares de memoria como turismo cultural y patrimonio a través de dos elementos clave: los restos, las marcas y los vestigios físicos de memoria de los conflictos recientes, y su capacidad de transmisión a través de diversos canales en el presente. Esta transmisión de lugares y vestigios de memoria se prsentan a través de algunos ejemplos, especialmente escogidos alrededor de proyectos en debate permanente con el eje de la resistencia como fondo, bien sea real o simbólica. En este caso, a partir de una visita a lugares memoriales y monumentos sobre resistencia en Italia y Alemania donde se pudo indagar sobre los perpetradores, memorias conflictivas, vestigios bélicos o no, memoria de las víctimas y sobre la transmisión y activación artístico-ciudadana. Se considera que el trabajo sobre memoria es un proceso permanente, comparado, en red y transnacional.

En torno a los lugares de memoria, espacios que transmiten nuestra historia del presente, son presentados en diversos modos: resignificados, conflictivos o simplemente interpretados para ser revisitados en el presente. $\mathrm{Al}$ respecto se plantean algunas reflexiones.

Los Espacios, lugares y discursos memoriales, se activan en nuestra sociedad de formas muy diversas y que son parte de iniciativas públicas o privadas, y que permiten analizar críticamente la capacidad de transmisión de ese pasado. Es así que el texto combina una aproximación analítica con ejemplos de lugares que «resisten y residen» en cuanto al patrimonio se tiene en cuenta el uso de la política de gestión -en los casos donde las haya- del pasado. Como se verá la disparidad es compleja. Se han escogido lugares, museos, monumentos, mausoleos, espacios, lugares o memoriales que realmente evocan episodios de resistencia a la barbarie, a las dictaduras $\mathrm{y}$ a las violencias que caracterizan la historia del siglo XX; y también otros lugares que implican una resistencia simbólica en el sentido que intentan -mediante diversos actores y procesos- resistirse a su desaparición o alteración por efectos de la manipulación, la mayoría por parte del poder o poderes que los fustigan. Hoy en día, la emergencia de nuevos actores, 
nuevos discursos y usos públicos de la memoria, incita a preguntarnos por el despliegue memorial como son los casos de Europa y América Latina para tener unos referentes. Este despliegue toma el relevo de un acontecimiento contemporáneo que modifica la memoria heroica o de duelo, fijada en el «deber de memoria", para enriquecerse bajo las formas más singulares y locales, por cruces e intercambios más allá de los Estados, y de las memorias nacionales. Así, la memoria toma fuerza como "derecho ciudadano". Los nuevos retos de memoria incluyen el trabajo continuo de historia y la rememoración a escala local, nacional, europea e internacional ${ }^{2}$. Es cierto que a escala local la memoria ha tomado una importancia capital, tanto desde el punto de vista historiográfico como de la colaboración entre instituciones locales y la colectividad para iniciar trabajos de memoria y patrimonio ${ }^{3}$. También es cierto que en algunos -no pocos-países, la memoria -o memorias-nacionales irrumpen en la esfera de intereses políticos y usos públicos muy encerrados en círculos de intereses propios, relatos únicos y narrativas peligrosas para la aceptación de la multiplicidad histórica e identitaria.

Se basa en el análisis de casos, la crítica de ejemplos aplicando la transnacionalidad de la memoria como proceso y

2 Geneviève Erramuzpé, "Informe sobre el proyecto de patrimonio y lugares de memoria comparados entre los países de Francia, Italia, Alemania» (conferencia presentada en Berlín, Red MEMORHA, 2007).

3 La proliferación de la historia local ha abierto un marco de estudio en lugares, donde el olvido y el silencio había imperado durante muchos años. Muchos de los centros de estudios locales o provinciales trabajaban sobre patrimonio cultural, historia y memoria pretérita y poco sobre los conflictos recientes contemporáneos. En España y muchos otros países la historiografía local gracias a los centros de Estudios Comarcales sobre la Guerra Civil Española o la represión del Franquismo han realizado una labor inédita e inmensa que ha favorecido el conocimiento del patrimonio memorial reciente, de la historia incómoda de los conflictos y las represiones. Puedo poner un ejemplo local, el Centro de Estudios Lacetans, comarca del Solsonés -Lérida, en España-, nunca se había ocupado de los desparecidos de la Guerra Civil o la dictadura, hemos podido contar las víctimas, y las fosas comunes, de los bombardeos, de la ocupación franquista, de los emboscados y sobre todo de la memoria oral de las víctimas así como la elaboración de mapa de fosas comunes y otras muchas investigaciones que gracias al impulso de políticas de memoria y a esa nueva historiografía local, se ha podido dar a conocer, publicar en revistas de investigación y divulgarse en portales de internent, socializando así la historia y la memoria. Ver: «Història,» Centre d'Etudis Lacetans, acceso en octubre de 2020, http://lacetans.solsonae.cat/seccions/historia. 
en los análisis comparativos. Por ello, a escala internacional, también nuevas formas de memoria emergen bajo el diseño que integra la transmisión de la historia, el debate público y la pedagogía social. Las Experiencias que se presentan en el texto, nos sirven para analizar las memorias transnacionales, debatir sus usos públicos, la evolución museográfica, las iniciativas sociales, la reflexión y experiencias, etc., de una forma comparada.

En las reflexiones sobre teoría y praxis, dentro de la administración pública, se ha planteado el concepto de memoria en red, si se tiene en cuenta un sinfín de ambientes y lugares, símbolos e íconos que sean capaces de activarlo en el espacio físico pero que incidan en el discurso público y ciudadano. De ello el concepto de Patrimonio Memorial se enrosca con el de memoria pública, memoria participativa o ciudadana. Un concepto que desde hace tiempo se estudia y se debate en la mayoría de países que han desarrollado políticas públicas de memoria (Europa, Latinoamérica, Sudáfrica, etc.).

Considerar la memoria democrática como Patrimonio colectivo se plantea con múltiples facetas por diversos autores. La memoria cultural y sus lugares, planteado por Andreas Huyssen, la memoria móvil, dinámica de Marianne Hirsch, los lugares como amplia definición conceptual, no solo física de Pierre Norá, y también y especialmente los no lugares o los contra-lugares y contramonumentos de memoria estudiados, pero también creados e impulsados por Joaquim Gerz, James E. Young, Andreas Huyssen, Marianne Hirsch o el mismo Horst Hoeisel. Todos ellos coinciden en que la memoria, en sus diversas y múltiples formas de transmisión configuran nuestro legado colectivo, nuestro patrimonio contemporáneo y como tal deben activarse a partir de amplios programas de políticas públicas y de participación cívica y social ${ }^{4}$.

4 Joachim Gerz, «La certitude et le rôle du temps» (videoinstalación y performance presentada en Représenter l'Irreprésentable?, 2015); Marianne Hirsch, «Mobilising Memory for Change» (Conferencia presentada en COST meeting, Budapest, Central European University, 2014); Andreas Huyssen, «Memoria cultural y derechos humanos» (Conferencia presentada en el Centro de Cultura Contemporánea de Barcelona, 2010); Andreas Huyssen, En busca del futuro perdido (México DF: Fondo de Cultura económica, 2002). 
Algunas experiencias nos ofrecen un ejemplo positivo a la hora de aplicar una política patrimonial con una correcta y unificada perspectiva de criterios y actuaciones, rehuyendo las espontaneidades excesivas faltas de contenidos dentro de los espacios territoriales que las afectan.

La lectura del patrimonio la interpreto muy amplia; no se limita solamente a la descripción histórica o tipológica de los objetos, también lo hace sobre sus significados y su función social. Por ello, la búsqueda de elementos simbólicos, de significaciones políticas e identitarias, así como el trabajo en un lugar y un espacio sobre el dolor, el duelo, el conflicto y el olvido, constituyen nuevas dimensiones de un patrimonio ligado a su pasado y en su memoria.

Como es sabido, una de las más tempranas reflexiones sobre los «lugares de memoria» le debemos al historiador Pierre Nora, que la conceptualizó e ilustrar a partir de una dimensión francófona, es decir: «la memoria de lugares -en el amplio sentido de la palabra-donde se expresaba la memoria nacional francesa" articulando una distinción entre estos lugares de memoria y el patrimonio ${ }^{5}$. Norá constató que la recuperación de la memoria en los últimos años y de los «lugares de memoria", tienen dos efectos inmediatos y directos: el primero, es el de crear una intensificación de los usos del pasado, usos políticos, usos turísticos y usos comerciales, todo acompañado de más de una década de efemérides conmemorativas en los diferentes países de Europa; el segundo, recibe el efecto de una recuperación actual de la memoria, más transversal que constata la desposesión al historiador del monopolio que tenía sobre la interpretación del pasado. La memoria se convierte colectiva y plural, compartiendo conocimiento con la disciplina histórica ${ }^{6}$.

Pero Norá, básicamente define los lugares de memoria no solo como los monumentos, los espacios, paisajes u objetos;

5 Pierre Norá, dir., Les lieux de mémoire. vol. 3 (París: Gallimard, 1984-1993).

6 Pierre Norá, «Reasons for the current upsurge in memory,» Transit Europaische Revue, $\mathrm{n}^{\circ} 22$ (2002), https://www.eurozine.com/reasons-for-the-current-upsurge-inmemory/. 
lo son también las fiestas, los emblemas, las conmemoraciones, los cantos, etc. En definitiva, todas las representaciones materiales o simbólicas portadoras de memoria. La materia y el símbolo se organizan y forman un sistema, una unidad orgánica, construyen la memoria de un grupo, de unos ciudadanos, los miembros de una nación.

Así pues, los lugares de memoria no son solamente lugares físicos. También lo son inmateriales, intangibles o abstractos. $\mathrm{Su}$ función en cuanto a patrimonio memorial, y el objetivo de los memoriales o instituciones de memoria en cuanto garantes de éste, es la transformación de la memoria del pasado en una cuestión crítica del presente gracias a un ejercicio colectivo de reflexión y de aceptación de la memoria como patrimonio colectivo y del derecho a la memoria como uno de los pilares de las sociedades democráticas contemporáneas.

En referencia a la interrelación de espacios de memoria es imprescindible la participación de varias disciplinas y varios objetivos que plantean los trabajos de memoria ${ }^{7}$ :

- Abordar las reflexiones de las redes profesionales de museos y memoriales sobre los retos actuales.

- Potenciar la colaboración entre las instituciones memoriales y las universidades que no se limita a los historiadores especializados, incorporando sociólogos, antropólogos, artistas, etc., que interesen por las dimensiones públicas del trabajo de memoria. Cambios y análisis inducidos por la diversidad y la circulación de públicos, de visitantes, de formación educacional, etc.

- Investigar sobre los roles que juegan las intervenciones artísticas, culturales y asociativas en el trabajo de memoria y en su recepción colectiva.

7 Iniciativa de M.O.D.Y.S, laboratorio de investigación sobre los MOndes et DYnamiques des Sociétés, trabaja con una comisión del CHRD de Lyon, el Memorial de la Maison des enfants d'Izieu, el museo Dauphinois y de la Resistencia de Grenoble y el CPIE de Vercors, el Museo Diffuso de Turín y la Topografia del Terror de Berlin. 
- Examinar procesos de institucionalización e implicación de los gestores públicos - políticos- en la planificación de las políticas de memoria.

Todo este proceso interactúa en estos Espacios de Memoria y de historia, que también lo son, de investigación y de comunicación o difusión. Espacios que nos llevan a una toma de conciencia basada, no en las sombras del olvido, sino en la necesidad de reflexión. Deben recoger el recuerdo, pero deben ser lugares donde la memoria trabaja, no sólo reflejan la historia o el recuerdo, han de ser su laboratorio.

La primera reflexión sobre los Espacios de Memoria nos sirve de alguna forma para pensar en las iniciativas que en todo el mundo, y no solo en Europa, surgen en la recuperación de monumentos, espacios y lugares de memoria como turismo cultural y como lugares de residencia que compartimos, a la vez que lo son de resistencia para evitar ser condenados al olvido.

\section{1. ¿Lugares de resistencia y memoria como espacios de turismo cultural?}

Cada vez más los espacios de memoria están catalogados como bienes patrimoniales. En algunas ciudades y países incluso están protegidos legalmente como bienes de interés local, regional o nacional. Otros de estos espacios están catalogados tanto por la UNESCO como por la UE, como Espacios Culturales o de Patrimonio Cultural, insertados dentro de organismos de gestión diversa dedicados a la protección del patrimonio histórico en el marco de una realidad más amplia llamada Paisaje Cultural ${ }^{8}$.

Patrimonio y territorio pasan a ser unos elementos clave para las estrategias de desarrollo local. Son lugares históricos de resistencia -porque fueron espacios vividos y protagonizados por resistentes al agresor y ocupante nazi

8 Conxita Mir, Josep Calvet y Joan Sagués, «Historia, patrimonio y territorio: políticas públicas de memoria en el frente del Segre y la frontera pirenaica catalana,» Hispania Nova, $n^{\circ} 6$ (2006): 1-25, http://hispanianova.rediris.es/6/dossier/6d009.pdf. 
durante la Segunda Guerra Mundial-y se han convertido en lugares de turismo cultural y memoria activa. Estos modelos los encontramos en el Parque Natural del Vercors en Francia, en el Parque de la memoria de Monte Sole en Italia o en el recorrido natural del Hospital de Partisanos de FRANJA de Eslovenia ${ }^{9}$.

El hospital de Partisanos de Franja, es una actuación de recuperación de patrimonio memorial, natural y cultural -arqueológico contemporáneo- paradigmático a la hora de intervenir en los espacios de memoria. En unas gargantas rocosas y escondidas, cerca de Cerkino y dependiendo del museo de Idrija, es un espacio que poco a poco se ha ido recuperando como lugar turístico sin perder el carácter y el respeto por la memoria local y nacional, incluso europea. En este hospital clandestino de resistencia durante la Segunda Guerra Mundial se atendieron más de quinientos partisanos o guerrilleros resistentes que luchaban contra los nazis ocupantes. Con un acceso único y un camuflaje natural en medio de las gargantas, el hospital nunca fue descubierto o delatado por la población local-que obviamente sabía de su existencia-. Es curioso ver cómo en un recóndito paisaje natural, envuelto de bosques, montañas y campos y habitado por campesinos y ganaderos, se pudo crear este espacio de resistencia contra el ocupante nazi. Los vecinos y vecinas, conscientes de la represión brutal por parte de las tropas alemanas y del peligro de ocultación que ello implicaba para los resistentes o "colaboradores pasivos", nunca delataron el lugar. La delación y la traición fue un común denominador del período de guerra y represión, por ejemplo, el triste episodio de la Maison d'Izieu ${ }^{10}$, donde más de cincuenta niños judíos refugiados fueron enviados a la muerte por culpa de una delación vecinal. En este sentido, Franja parece ser que fue la excepción. A nivel de uso patrimonial y turístico, durante las diferentes etapas posteriores, la población y los gobiernos han actuado en este espacio, recuperándose definitivamente

9 Idrija Municipal Museum, acceso el 06 de marzo de 2020, https://www.muzej-idrijacerkno.si/en/. También: Pierre Weick (director del Parc Naturel Régional du Vercors), entrevista por Jordi Guixé, noviembre de 2006.

10 Maison d'Izieu, acceso el 06 de marzo de 2020, https://www.memorializieu.eu. 
a partir de 2007, cuando una riada dañó gran parte de las barracas originales y los accesos. Fue la participación y la iniciativa de los vecinos quienes voluntariamente iniciaron su recuperación, restauración y recreación museográfica como patrimonio, natural, local y memorial.

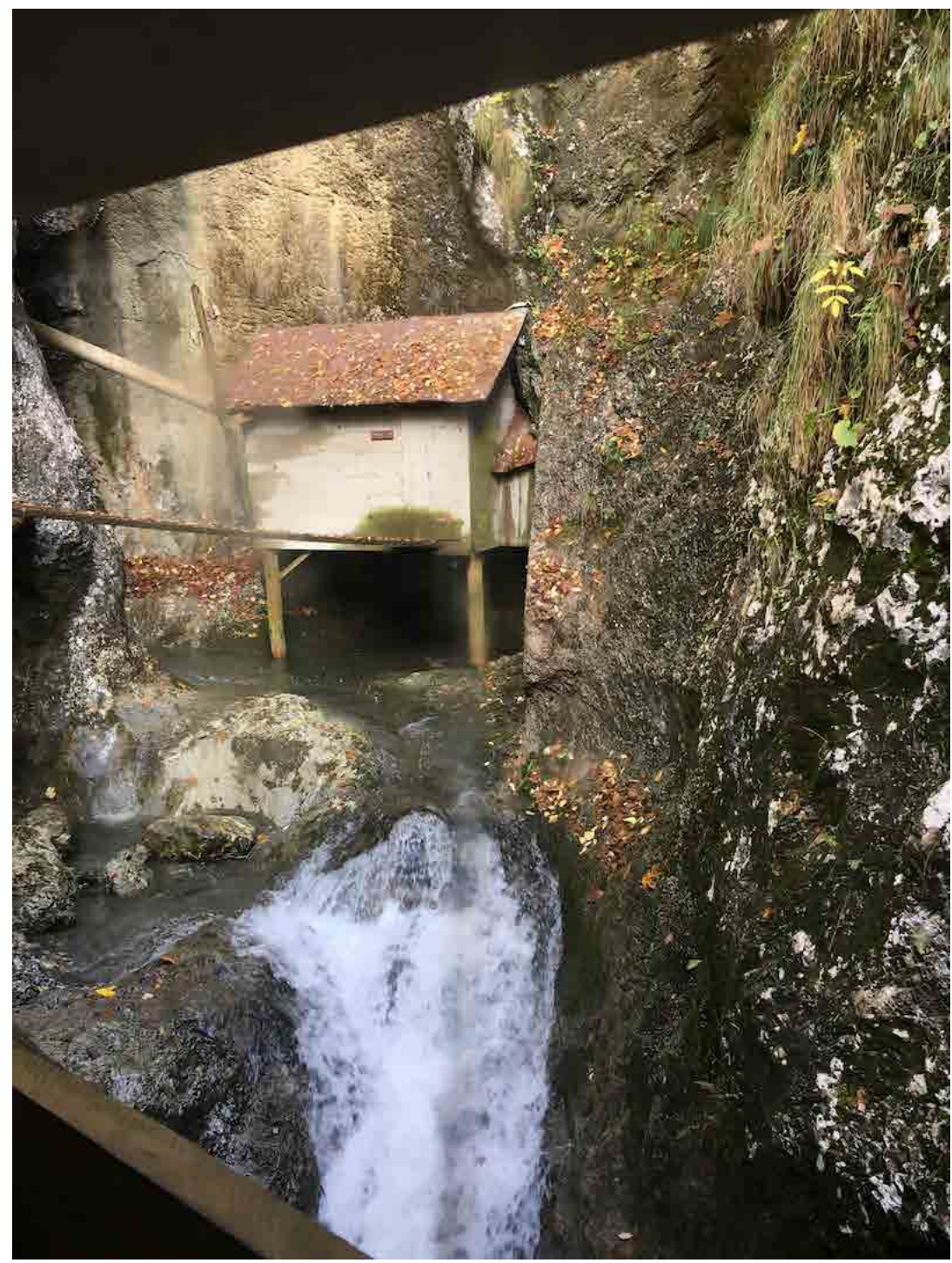

Imagen: Memorial-Museo del Hospital de Partisanos de Franja, Eslovenia.

Fuente: Foto tomada por el Autor. 


\section{Vestigios que resisten como marcas de memoria}

Es por ello importante y básico poder analizar las relaciones que se establecen entre historia, patrimonio cultural, turismo y territorio a través de la recuperación de la memoria. La diversidad de acciones y participaciones de colectivos con intereses profesionales diversos, políticos $\mathrm{y}$ emocionales diferentes hacen necesario que la política pública tienda a regular. Estas acciones diversas van desde la investigación histórica, pasando por iniciativas legislativas, conmemoraciones, hasta las intervenciones señaléticas, memoriales y museográficas.

Igualmente, los espacios asociados a actividades bélicas se presentan como vestigio material recuperable. Por varios motivos: por su relevancia histórica, por el valor museográfico, por su contenido patrimonial, el patrimonio bélico y resistente es especialmente destacable: trincheras, búnkeres, fortificaciones, cárceles, campos de aviación, refugios, y otros elementos, entre los que se debería empezar a apuntar las necrópolis de guerra y las fosas comunes -civiles o militares- como lugares patrimoniales, visitables y, sobre todo, dignificables.

Pero no solo los vestigios materiales son el objetivo de una política memorial donde los referentes democráticos sean el eje. Es evidente que las guerras han marcado espacios amplios susceptibles de recuperar, tal vez algunos de restaurar y reconstruir, pero el patrimonio bélico puede tener muchas lecturas y hay que ir con cuidado como transmitirlo y mostrarlo. Con frecuencia se puede caer en la exclusiva tematización bélica, de un gran contenido traumático pero que a veces presenta carencias o líneas rojas sobre los valores transformadores, por ejemplo, del antifranquismo, el antifascismo. $\mathrm{O}$ bien, como vemos en muchos museos militares o de historia militar con la aparición de ciertas narrativas nostálgicas que pueden ser nocivas a la cultura democrática y el trabajo pedagógico que se deriva, especialmente con los más jóvenes. Cómo analizar la problemática de la proliferación ingente -cita exagerada- de museos militares en China o en 
Irán (más de 150 en cuatro años sobre la temática). O cómo abordar el trabajo pedagógico en un museo sobre los «Tanques alemanes» en medio de la Europa democrática? ¿O como lidiar con los más de trescientos mil visitantes escolares en el museo del Levantamiento y resistencia de Varsovia, repleto de armas y de acciones bélicas, incluso con exposiciones temporales sobre la armada polaca en Oriente Medio? Son preguntas difíciles de resolver pero que en la visita, tanto profesional como neófita de estos lugares, nos plantean muchas dudas acerca de la capacidad de transmisión de valores universales, entre otras cuestiones obvias sobre qué mensaje político y social se esconde detrás de estas narrativas museológicas. Estas son cuestiones básicas que nos dan elementos de análisis y de alarma sobre las temáticas bélicas que fueron tratadas -entre muchas otras- en el penúltimo congreso internacional del ICOM-ICMEMO en Milán en julio de $2016^{11}$.

La visita de los lugares de memoria participa de un trabajo previo: el trabajo de memoria como proceso de reflexión. Así el turismo de memoria permite un trabajo pedagógico y no solo para recordar y conocer, también para aceptar lo que pasó y para recuperar valores ignorados por etapas represivas y episodios resistentes. Todo hace parte de un gran ritual necesario para la paz social donde se reencuentran las conciencias individuales con las colectivas ${ }^{12}$.

Una vez establecida la política y sus objetivos, el siguiente paso hace referencia al trabajo de recuperación memorial: inventario territorial de espacios de memoria, lugares, citas e itinerarios posibles para constituir un programa. Este programa permite elegir y establecer los objetivos más concretos para ser desarrollados o definidos como base para un trabajo de transmisión memorial y para evitar la banalización a través de los errores de contenido o el uso y actitudes frívolas de los visitantes desinformados.

11 «Icmemo annual conference,» ICMEMO, acceso el 06 de marzo de 2020, http:// icmemo.mini.icom.museum/wp-content/uploads/sites/17/2019/01/Report_ICMEMO_ Conference_2016_Milan.pdf.

12 Jean-Didier Urbain, «Tourisme de mémoire, un travail de deuil positif,» Espaces, $\mathrm{n}^{\circ} 80$ (2003). 
Los estados democráticos europeos y occidentales han seguido diferentes estrategias de señalización, conmemoración y memorialización de espacios, muchos referentes casi siempre en victorias o derrotas vividas durante las dos grandes guerras del siglo XX, pero también muchas otras guerras y conflictos. Esta política es interpretada en el ámbito local como un medio también de desarrollo cultural y de recursos.

\section{La transmisión}

Francia y Alemania son dos referentes en redes de museos y memoriales y allí también se ha generado un debate amplio sobre la constante renovación de contenidos, de señalización y de banalización o no de los espacios memoriales a través del turismo cultural. Pero también se han iniciado procesos similares a muchos otros países no europeos como, por ejemplo, la Red Federal de Sitios de Memoria, que se impulsa en Argentina ${ }^{13}$. En los países donde se han sufrido dictaduras más recientes, por ejemplo, Latinoamérica, se han expandido los proyectos memoriales y la señalización de elementos recordatorios de hechos represivos o de resistencia-Placa, monolito, inscripción, espacio... -. Un nombre chileno define como "señal ética»" los espacios de memoria. Este concepto que se debería trabajar más a fondo, tal vez en Europa y puede servir de referencia a la hora de valorar la función de difusión patrimonial y de gestión de usos públicos de nuestro pasado reciente.

Ahora bien, la tematización excesiva y la obsesión por crear recursos no debe alejarse del trabajo de memoria. Lo que debemos evitar son los recursos monumentales de petrificación de la memoria que mira al pasado. Se ha de erigir y señalizar con una clara función de transmisión ética y de pedagogía social en el presente fugaz y de cara al futuro. Se debe evitar esta petrificación y favorecer la movilidad y

13 Red Federal de Sitios de Memoria de Argentina, acceso el 06 de marzo de 2020, https://www.argentina.gob.ar/archivonacionaldelamemoria/direccionsitios.

14 Ricard Vinyes, «Informe sobre les polítiques públiques de reparació i memòria a Argentina i Xile. Una aproximació comparativa» (informe inédito presentado en Barcelona, Dirección General de Memoria Democrática, 2006). 
dinamismo de las instituciones, centros de interpretación o espacios. Lo primero que me planteo cuando visito un espacio memorial es si tiene un discurso cerrado y concéntrico con una narración inmóvil aún doctrinal. Es difícil rehuir el aspecto moralizador de ciertas exposiciones. Estas -si es que son necesarias- deberían ir acompañadas de un plan de usos y actuaciones, al respecto con criterios compartidos con otras instituciones $\mathrm{u}$ organismos competentes, convirtiéndose en proyectos de máxima transversalidad que son los que llegan al ciudadano realmente. La administración pública tiene la responsabilidad de garantizar a los ciudadanos el derecho a conocer y valorar los espacios memoriales, requiere situar y garantizar en el espacio público el ejercicio de este derecho, explicitarlo y democratizarlo.

La transmisión es sin duda la articulación de un relato memorial en el espacio y el tiempo presente, bien sea a través de lo que yo llamo "grandes equipamientos memoriales y culturales», o bien con el marcado o intervención artística o arquitectónica en el espacio público. Todos los ejemplos recogidos en el presente texto quieren mostrar modelos comparativos y referentes de forma paralela, siendo conscientes de que el trabajo de memoria es conflicto y debate permanente. Sin este debate la memoria se banaliza o se frivoliza, llegando a lo que se ha definido como memoria buena -o buenismo memorial-. Este obliga a expresar un relato repetitivo que siempre termina con la misma moraleja final sobre la «paz en el mundo", obviando los trayectos del conocimiento histórico y la importancia del recuerdo en la construcción de una sociedad democrática, social y cívicamente más sabia y, por lo tanto, más libre.

Así pues, los casos mencionados son referentes simbólicos de actuaciones que considero satisfactorias en el trabajo de memoria, patrimonio y política pública. Como verá el lector, no están ausentes de déficits o polémicas, que serán brevemente introducidas. Es un análisis de proyectos que pretende ir más allá de un simple inventario. Los espacios memoriales se activan conjuntamente con la necesidad de comunicación y divulgación de la memoria y su patrimonio, 
tangible o intangible. Este actúa en nuestra sociedad en calidad de conocimiento cultural, recorrido pedagógico para las nuevas y viejas generaciones, y también en el campo del turismo cultural o turismo memorial, como he citado ${ }^{15}$.

Parte del debate teórico también se ha traducido en el tratamiento del patrimonio. Actualmente podemos constatar lo que apuntaba Nora en su amplio estudio en el que utilizaba un concepto amplio de "lugar de memoria» (incluyendo una bandera, un himno, etc.). Pero cuando se aborda el reto de la transmisión del pasado en el presente interesa hablar sobre espacios con una concreción geográfica, léase lugares originales, un lugar de memoria histórica, seguido de un programa concreto de actividades y visitas, y una relación simbólica con la sociedad; tal vez están relacionados con lugares de recuerdo y conmemoración o con un lugar de nueva ubicación, pero con análogas funciones. Estas diferencias las encontramos si condicionamos la definición de espacio de memoria al uso social de este espacio, si se establece o no una dialéctica con el colectivo -la memoria colectiva, o memoria cultural, como la define Andreas Huyssen- los que lo han hecho objeto depositario de su recuerdo ${ }^{16}$.

Hay una aplicación del modelo local directo al intercambio internacional. Se ha descubierto en los últimos diez años que, a escala regional, la historiografía de los lugares de memoria y su dinamización cultural y patrimonial han revelado nuevos usos y discursos memoriales con relación a la transmisión y la renovación generacional, lo que llamaríamos las segundas generaciones, o las terceras. Igualmente, cabe destacar la importancia de las asociaciones y colectivos territoriales en la institucionalización de estas memorias. Como se ha sugerido, a escala internacional, las diferentes maneras de conmemoración responden a estos usos públicos de la memoria, que, si no se quiere que caigan en rituales asépticos, deben contar con este componente local y regional

15 VV.AA., «Cahier Tourisme de Mémoire,» Espace, nº 313 (2013): 3-96; VV.AA., «Dossier: Le Tourisme de Mémoire,» Ancrage, (2008).

16 Huyssen, «Memoria cultural y derechos humanos». 
de nuevas formas de interactuación. En Europa, el trabajo de memoria está en función de los contextos históricos nacionales (Francia, Alemania, España, Italia, los nuevos países del Este, etc.), así como en relación con la construcción europea que es la que genera transnacionalidad. La relación entre historia y memoria gana fuerza y protagonismo en las nuevas formas de construcción pública de memorias de la guerra y la resistencia, que se vislumbran entre la transmisión histórica, el debate público y la pedagogía social.

\section{Espacios de memoria, Modelos y sus debates}

\section{El complejo caso italiano}

Vestigios de la Línea Gótica: Si nos aproximamos al espacio italiano, encontramos un proyecto de territorio y memoria en forma de amplio itinerario llamado Línea Gótica. La Línea Gótica es un proyecto ambicioso de turismo cultural y memorial que quiere conectar, a través de un recorrido señalizado y continuo el mar Tirreno con el Adriático, pasando por las regiones de Liguria, Toscana y Emilia Romagna. Históricamente la Línea Gótica fue la zona de frontera fortificada, que durante un año crearon los nazis y donde se estableció el frente de guerra. Una línea llena de vestigios bélicos, pero que también explica la brutal e implacable represión que los alemanes ejecutaron contra la población civil, y los resistentes o partisanos que nunca dejaron de actuar en la zona. Las masacres, violaciones, torturas y fusilamientos indiscriminados salpican el territorio. Una zona que al final fue liberada con ayuda de los aliados en $1945^{17}$.

El proyecto incluye lugares y espacios de memoria que existen desde hace años: estelas, cementerios y algún centro de interpretación, pero también quiere ser un itinerario cultural y natural por muchos de los parajes que atraviesan los Apeninos. Este itinerario incluye también la recuperación de algunos elementos bélicos de la Segunda Guerra Mundial.

17 Vito Paticchia, Guerra e Resistenza sulla la linea Gotica Tra Modena e Bologna, 1943-1945 (Modena: Edizioni Artestampa, 2006). 
La Región de la Toscana y de Emilia Romagna, ya han editado libros y guías históricas y turísticas para indicar a los visitantes el itinerario, pero falta un acuerdo supramunicipal para coordinar los esfuerzos y crear un proyecto de gran empuje. Ya desde 2008 en Bologna se inició la recuperación y promoción de la ruta y los itinerarios y fue el impulso decisivo para el proyecto. Este destaca la capacidad de activación de esta ruta memorial aprovechando el potencial cultural y turístico de visitantes. aprovechando ciudades con una tradición muy grande de acogida como son Florencia y Bolonia. Esta activación cultural no contradice el trato memorial que determinados puestos de duelo deben mantener y potenciar, especialmente las ruinas de la población masacrada de Marzzaboto, que incluye cementerios y fosas comunes. El conjunto presenta un buen ejemplo del trabajo transversal de memoria, historia, patrimonio y turismo digno de tener en cuenta $^{18}$.

\section{Memorias y nostalgias conflictivas en Predappio}

Predappio a primera vista tiene una carga difícil y compleja de nostalgia fascista. Lo primero que viene a la memoria son los reportajes periodísticos y conmemorativos sobre las largas peregrinaciones de grupos neo-fascistas y de extrema derecha, que van a rendir culto al símbolo, al líder y a su memoria. En Predappio nació Benito Mussolini donde también está enterrado en un panteón familiar privado en el cementerio municipal. Lugar de adoración y peregrinación, el trayecto que recorre entre la casa natal de Mussolini y su tumba, se encuentra la avenida principal del pueblo que está rellena de tiendas con íconos y suvenires turísticos propagandísticos nazifascistas y franquistas, que quizás deberían estar prohibidos en una democracia sana y profiláctica. Pins, bustos y estatuas, etiquetas de vinos, banderas, medallas, fotografías,

18 Alguna de estas conclusiones fueron presentadas en el congreso internacional: «Territori e memorie. Esperienze e progetti europei a confronto, GAL dell'Appennino bolognese e Comunità montane nell'ambito del progetto "Linea Gotica: patrimonio storico-culturale dell'Appennino bolognes"» (Congreso internacional en Bolonia, 28 de marzo de 2008). 
libros ... incluso en las cafeterías de la calle principal venden un «polo helado» llamado Benito.

En medio del recorrido, un edificio imponente, vacío, parece abandonado. Es la antigua Casa del Fascio. Hogar y origen del fascismo político (dicho popular) en los años 20. Un edificio de estética racionalista que ahora es el motivo de una gran controversia memorial en toda Italia en función de su proyecto de usos. El anterior alcalde de Predappio, Giorgio Frassinetti, hace años que ha creado una comisión y un Proyecto para convertir la Casa del Fascio en un espacio único en Italia sobre la memoria del fascismo. «En Predappio empezó todo», afirma el ex-alcalde ${ }^{19}$. Tanto él, como la comisión científica dirigida por el profesor Marcello Flores, no han parado de buscar promotores, ayudas y colaboradores para el proyecto a nivel nacional e internacional ${ }^{20}$. En el diverso universo histórico memorial italiano, parecía que había un cierto consenso sobre el proyecto. Llegamos a verano de 2019 con dos retos importantes para el proyecto, que me atrevería a definir de crítico. Por un lado, Franssinetti había podido reunir más de cuatro millones de euros para comenzar las obras, aún y teniendo la comunidad historiográfica e intelectual italiana dividida entre partidarios y detractores -como no podía ser de otra forma-. El proyecto en sí mismo es valiente, incluso de resistencia política, sobre todo ahora que por primera vez en el municipio gobernará la derecha radical de la Liga. La encrucijada engendra muchas dudas sobre el lugar mismo y sobre el futuro del proyecto: ¿cómo tratar la memoria y la historia del fascismo, en un lugar «original» con tantas connotaciones nostálgicas? ¿Como es de peligrosa la interpretación democrática del pasado violento e injusto en un lugar donde públicamente se muestra la exaltación de la barbarie? ¿Cómo hacerlo?, es el

19 Giorgio Frassineti (alcalde de Predappio), entrevista por Jordi Guixé, 26 de mayo de 2015. La entrevista se encuentra accesible en: «Citizen's voice,» European Observatory on Memories, acceso el 06 de marzo de 2020, https://europeanmemories. net/video-category/citizens-voice/.

20 Marcello Flores y Carlo Giunchi, «Predappio and the memory of the dictatorship,» Observing Memories, ${ }^{\circ} 3$ (2019): 22-27, https://europeanmemories.net/magazine/ predappio-and-the-memory-of-the-dictatorship/. 
dilema. ¿Dónde hacerlo?, también. Recordemos que, en 2012, la tumba de los padres de Hitler -Alois i Klara Hitler- fue desmantelada por el ayuntamiento de Leonding en Austria, para evitar peregrinaciones nostálgicas neonazis en el pueblo y concretamente en la iglesia de San Miguel de dicha localidad. $\mathrm{Al}$ parecer una familiar descendiente de Alois pidió también el desmantelamiento de la estela y de su inscripción.

Predappio está pues en medio de la polémica, algunos comienzan a defender que se haga derruir la casa del Fascio y se olvide el proyecto. Tal vez, hacerlo sería dar la razón a aquellos que ya tienen su lugar físico y simbólico de peregrinación en Predappio y se les concedería la exclusiva. Tienen la casa museo y tienen el panteón privado. Quizás que el resto de ciudadanos podamos disponer pronto de un espacio de aprendizaje, reflexión y análisis crítico de lo que fue uno de los orígenes de las catástrofes del siglo XX, pero la política y sus derivas sentenciarán, una vez más, a ese lugar a la polémica constante.

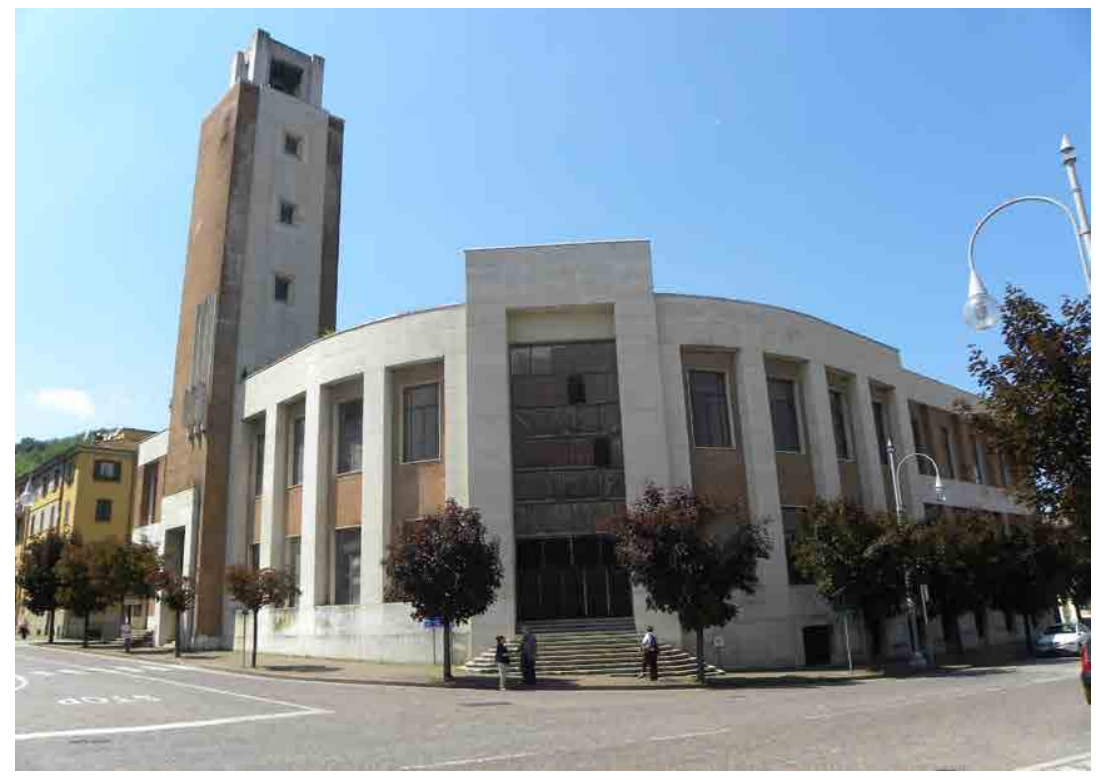

Imagen: Casa del Fascio en Predappio. Edificio donde se debe ubicar el nuevo Museo Memorial sobre el Fascismo.

Fuente: Foto tomada por el autor. 


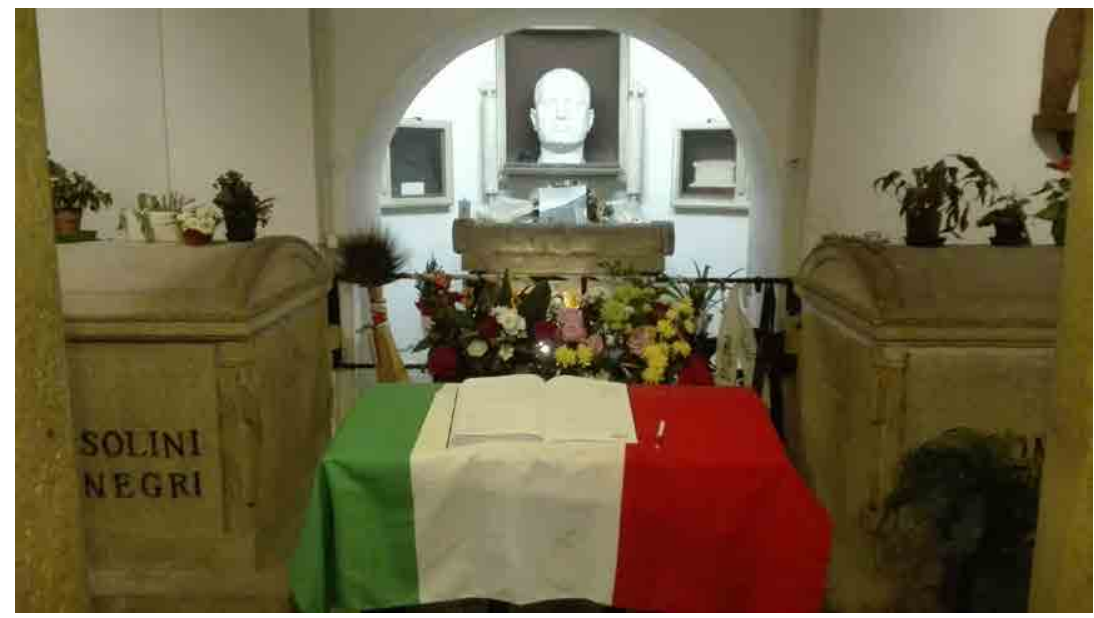

Imagen: Cripta y tumba de Benito Mussolini y su familia.

Fuente: Foto tomada por el autor.

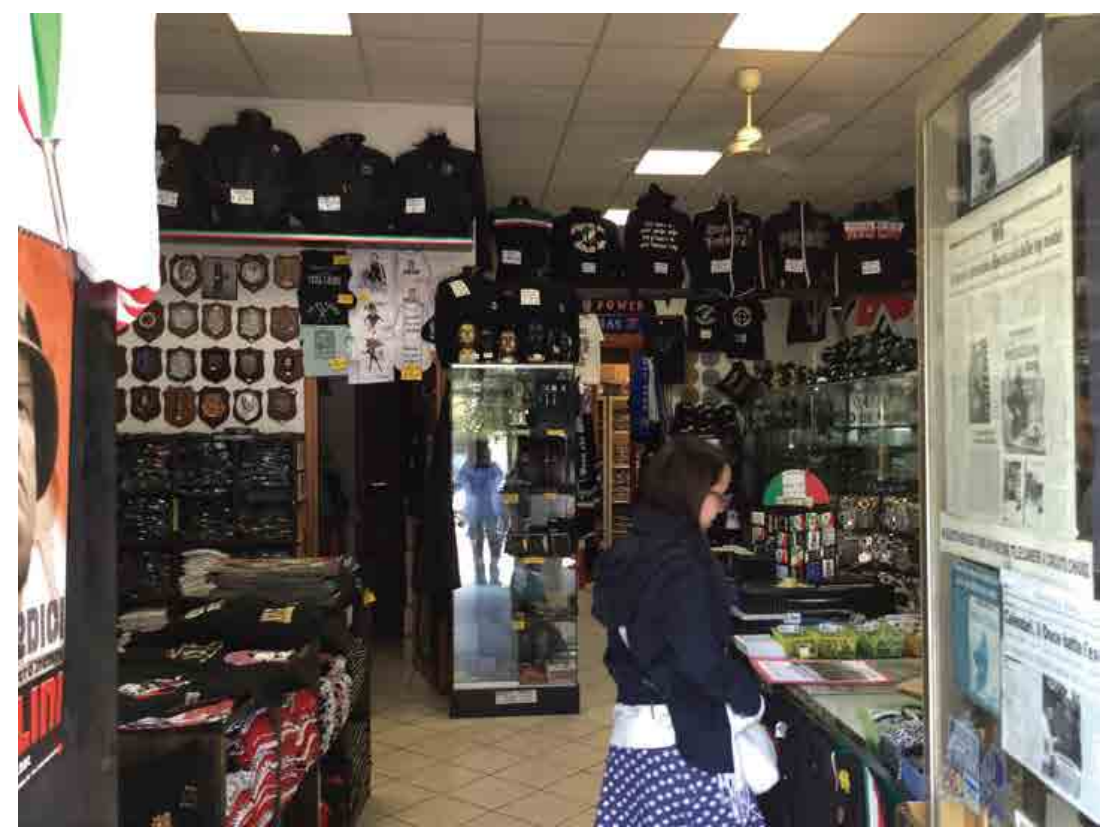

Imagen: Tienda de «souvenirs» nazifascistas en Predappio. Fuente: Foto tomada por el autor. 


\section{Alemania (Berlín), amalgama memorial entre la represión, las víctimas y los resistentes}

Como afirma el filósofo Xavier Antich respecto a Berlín: «En pocos lugares del mundo, el trazado de la ciudad se ha esforzado para hacer visible, de manera tan planificada, las heridas de su pasado» ${ }^{21}$. Efectivamente, la ciudad de Berlín se erige como ejemplo integral de memoria democrática, ya que concentra un gran número de espacios relevantes para la historia de Europa del siglo XX y para la historia de la democracia europea.

Después de la Segunda Guerra Mundial, Europa se encuentra dividida, y Berlín edificó el símbolo de esta división. La Alemania federal (RFA) y la Alemania bajo el bloque comunista (RDA) aplican diferentes perspectivas memorialísticas en su territorio, de acuerdo con sus principios políticos e ideológicos, en los que se fundamentan los respectivos gobiernos hasta la unificación. Así, mientras que en la RDA se exaltó la lucha antifascista y la liberación de campos por parte de las tropas soviéticas, la constitución de 1949 de la RFA cedió las competencias en materia de cultura a los lands o estados federales, construyendo, así, desde la década de 1950, una red de museos de historia de gran calidad y efectividad ${ }^{22}$. En los años setenta, las generaciones más jóvenes de la Alemania federal, herederas del sentimiento de culpabilidad nacional, manifestaron un gran interés y deseo de saber más sobre su pasado reciente, la historia del Tercer Reich, la memoria del terror nazi y del Holocausto. Por eso la política cultural y la museística, con una cierta presión mediática, consideró la necesidad de desarrollar un nuevo tipo de museos, centros culturales o memoriales. Con la caída del muro, en 1989, y la reunificación de la ciudad de Berlín, la rápida reacción del gobierno local, apostando por una clara política conservacionista de los espacios de esa

21 Xavier Antich, «Berlín, capital del duelo», Culturas [suplemento de La Vanguardia], Barcelona, 29 de junio de 2005, 2-7.

22 Miquel Serrano y Maximiliano Fuentes, «Seminaire d'étude en Allemagne, Histoire, mémoire, transmission. Lieux d'Histoire et de Mémoire: Berlin-Ravensbrück» (seminario del 10-16 de diciembre de 2007), inedito. 
historia reciente, permitió esta vez planificar los espacios memoriales. Berlín se erige hoy en día como ejemplo de ciudad protagonista de los principales acontecimientos históricos del siglo XX en Europa, ha sabido gestionar la memoria y sus espacios, respondiendo a las peticiones de la población y a unas decididas políticas públicas de memoria. Los memoriales de Berlín tienen su origen sobre todo en dos procesos históricos acaecidos durante el siglo XX, los anteriores a la Segunda Guerra Mundial (repercusiones de la Primera Guerra Mundial y dictadura nacionalsocialista) y los posteriores a la guerra (Berlín de la guerra Fría y de la post unificación de 1991). El grueso de los memoriales de Berlín son alrededor de la memoria de la dictadura nazi y sobre todo del holocausto judío, aunque también queda todavía y se tiene en cuenta la memoria del Berlín de la RDA, basada en el anticapitalismo y la resistencia antifascista.

En Alemania, una red menos coherente en cuanto a gestión, pero incomparable como tejido urbano de espacios de memoria, la encontramos en Berlín, ciudad de referencia en cuanto a la multiplicación de proyectos de memoria en el espacio público. Desde hace más de cincuenta años, sus urbanistas, políticos, filósofos, historiadores, ciudadanos de la más diversa índole, han acumulado un tesoro de reflexiones conflictivas y de experimentaciones sobre la manera de representar la memoria. Años después de la Segunda Guerra Mundial, (dicen que hacia los años setenta) se comenzó a explicitar en el espacio público la memoria de la Shoah y el Holocausto. Pero no fue la única memoria patrimonializada, y Berlín se ha convertido en un referente también en el marco de la nueva museología, el arte contemporáneo y las instalaciones en particular. Como muy acertadamente afirma Régine Robin, Berlín es hoy en día, un laboratorio, una cantera donde se experimentan nuevas identidades, diferentes discursos sociales. El memorial del Holocausto actualmente comparte reflexión con los espacios de memoria y represión del Berlín Este, de la antigua República Democrática Alemana. De hecho, la unificación alemana ha llevado a la reflexión sobre la diversidad de memorias, manteniendo bien presentes los trabajos sobre el nacionalsocialismo y el comunismo 
como ejercicios de recuerdo, atrocidad y duelo, quizás no compartidos, pero sí comunes.

\section{Entre los símbolos nazis y la reunificación}

Muchos memoriales y monumentos existen sobre el terror nazi, centros de documentación sobre el nacional socialismo, que proliferan en todas las ciudades alemanas (recomiendo el recién inaugurado en Munich), campos de concentración convertidos en museos memoriales y un sinfín de iniciativas. Pero sobre el horror nazi, sobre sus símbolos y el rol de los perpetradores, me gustaría hablar del poco conocido memorial del castillo de Wewelsburg. Situado en el distrito alemán de Paderborn, que fue construido en el siglo XVII en estilo renacentista como residencia temporal para los príncipes obispos de Paderborn. En 1933, el líder de las SS, Heinrich Himmler, hizo construir un centro ideológico en el castillo de Wewelsburg, que se remodeló y convirtió en un lugar de reunión exclusivo para oficiales de alta graduación de las SS. Himmler, se alojó a menudo en el castillo, que se convirtió en el punto de encuentro ideológico y ritual para sus SS. Por otra parte, en el pueblo de Wewelsburg se estableció un campo de concentración para prisioneros; se trataba de un campo de trabajo independiente, que funcionó de manera similar a los de Buchenwald, Sachsenhausen o Dachau. El castillo acoge actualmente la exposición "La Ideología y el Terror de las SS» en una nuevo espacio, y se recuerda así a todas las víctimas de la violencia nazi, pero también, y sobre todo, (tal como hace la Topographie del Terror en Berlín), la memoria y el papel de los perpetradores o verdugos. Es interesante ver cómo esta nueva exposición permanente (remodelación del memorial, que ha costado treinta millones de euros, pagados entre el gobierno del Land y del Estado) muestra o interpreta los símbolos, signos y formas materiales o testimoniales de las antiguas SS. Para ello encontramos muchas piezas difuminadas dentro de cristales medio biselados, para evitar la agresión directa del símbolo nazi ante el visitante o espectador. Igualmente, se ha planteado una solución cuidadosa en el debate sobre la reutilización del símbolo nazi del Sol Negro, todavía ubicado en su lugar original en una de las torres del castillo. Actualmente 
se visita el espacio como lugar de reflexión sobre la perplejidad del presente y la reutilización de ciertos símbolos e iconos ${ }^{23}$. El Sol Negro es un símbolo inscrito en un mosaico de mármol y silicio negro que está relacionado con la filosofía ocultista del nazismo. En alemán es Schwarze Sonne; también se refiere al término Sonnenrad (en alemán, 'rueda solar'), símbolo de esoterismo y de significado oculto, notable por su uso en el misticismo nazi y sobre todo alrededor de las SS y Himmler. El sol negro es un símbolo esotérico compuesto por dos círculos concéntricos. El círculo interior posee la forma de un sol del que parten doce rayos (que en la concepción clásica de la rueda solar representaban el movimiento del sol a través del año). Los doce rayos, en sus extensiones, conforman el círculo exterior, donde sus ángulos se tuercen formando al mismo tiempo dos símbolos de importancia clave en el misticismo nazi: la esvástica y los rayos de la victoria, que doblados fueron utilizados como emblema de las $\mathrm{SS}^{24}$. El sol negro es un símbolo utilizado hoy en día por las ideologías neonazis y plantea un debate en dicho espacio memorial sobre el ritual nostálgico, que en algunos visitantes genera dicha exposición -tal y como hemos visto en Predappio-.

Si viajamos hacia finales de los años ochenta, abordamos la unificación alemana a través de uno de los memoriales más activos sobre la represión y la exclusión más destacados y contemporáneos, de gran repercusión internacional, el Memorial del Muro de Berlín. Un espacio dinámico, con una historia de memorialización social, reivindicativa y participativa, pues ya en los años 90, diversas entidades y vecinos evitaron la completa destrucción del Muro para poder "preservar la memoria». El director de la Fundación Memorial del Muro de Berlín, Axel Klausmaier nos recordaba que su trabajo ingente de memoria tenía conexión con el presente y se vivía como un proceso en construcción permanente, sin

23 Ver al respecto el sitio web: KreisMuseum Wewelsburg, acceso el 06 de marzo de 2020, https://www.wewelsburg.de/.

24 «Kirsten John-Stucke "Wewelsburg Castle - an attraction pole of Dark Tourism - How to deal with this phenomenon at a memorial site", 5th July 2016,» ICMEMO, Annual Conference, paper, acceso en noviembre de 2020, http://icmemo.mini.icom. museum/documents/papers/. 
el trabajo sobre el presente, Klausmaier afirmaba que su trabajo memorial no tenía sentido. Y es que el Memorial del Muro de Berlín es un memorial vivo, participado de la ciudad y la ciudadanía, rico en debates y en luchas para lograr la permanencia de una memoria incómoda para algunos pero que no quiso desaparecer para los vecinos. Uno de los agentes más activos en la defensa de la permanencia del muro y de un memorial de más de 1.7 kilómetros de longitud, fue Manfred Fisher, que desde el decreto de la demolición del muro -aprobado el 13 de junio de $1990^{25}$ - luchó por preservar vestigios y partes del muro como patrimonio colectivo y ciudadano para evitar el olvido y para evitar «más muros». Fisher, ante las presiones para demoler completamente todo resto de muro afirmaba: «Necesitamos algún resto físico y material para poder comprender lo que pasó y significó». Él mismo, defensor de la memoria tangible, resistió y se plantó ante los Bulldozers a la desaparición total del muro, cuando en los años noventa se había tomado la decisión de demolerlo. De igual manera actuaron los vecinos ante la primera propuesta de musealización, que pretendía sustituir el muro original por una escultura "mural y simbólica» en forma de barrotes verticales de hierro corten. Estos grupos de ciudadanos presionaron a los gobiernos berlineses que impulsaron los concursos arquitectónicos de los años 1998-1999. El resultado de éstos fue determinante para la supervivencia de vestigios originales y convertirlas en memorial.

El Memorial del Muro de Berlín y su Fundación es un ejemplo a seguir en la resignificación y transmisión del patrimonio memorial. Varios tipos de edificios, monumentos, intervenciones arqueológicas, arquitectónicas, artísticas, testimoniales y museográficas están representadas desde esa primera preservación de los años noventa. No como una voluntad ecuménica, sino porque los impulsores lo ven y lo viven como un proceso abierto. De acuerdo con Klausmaier, «un memorial cerrado se petrifica, un memorial en proceso

25 «LA DEMOLITION DU MUR ET LES VESTIGES AUJOURD’HUI,» Mémorial Du Mur De Berlin, https://www.berliner-mauer-gedenkstaette.de/fr/la-demolitiondu-mur-51.html. 
constante de evolución y acción dignifica y ejemplifica sobre el pasado presente». El proyecto fue evolucionando hasta mantener alguna torre, rehacer la iglesia como símbolo reconstruido del pasado y de la acción vecinal, o el campo de cereal que todavía se cultiva y se cosecha en una ceremonia simbólica y memorial realmente efectiva, en medio de Bernauerstrasse $^{26}$.

El proceso se vio definitivamente consolidado con el nacimiento de la Fundación en 2009 y la reciente conmemoración del 25 aniversario en 2014 (30 aniversario en 2019) ${ }^{27}$ y su ampliación con la creación de dos centros de documentación y exposición. También es curioso que parte de su financiación provino y proviene de los beneficios de la lotería nacional alemana. Así pues, el muro de Berlín y sus memoriales -en plural, ya que gestiona actualmente más de 25 espacios de memoria en la ciudad de Berlín-, son un ejemplo y un ícono europeo e internacional.

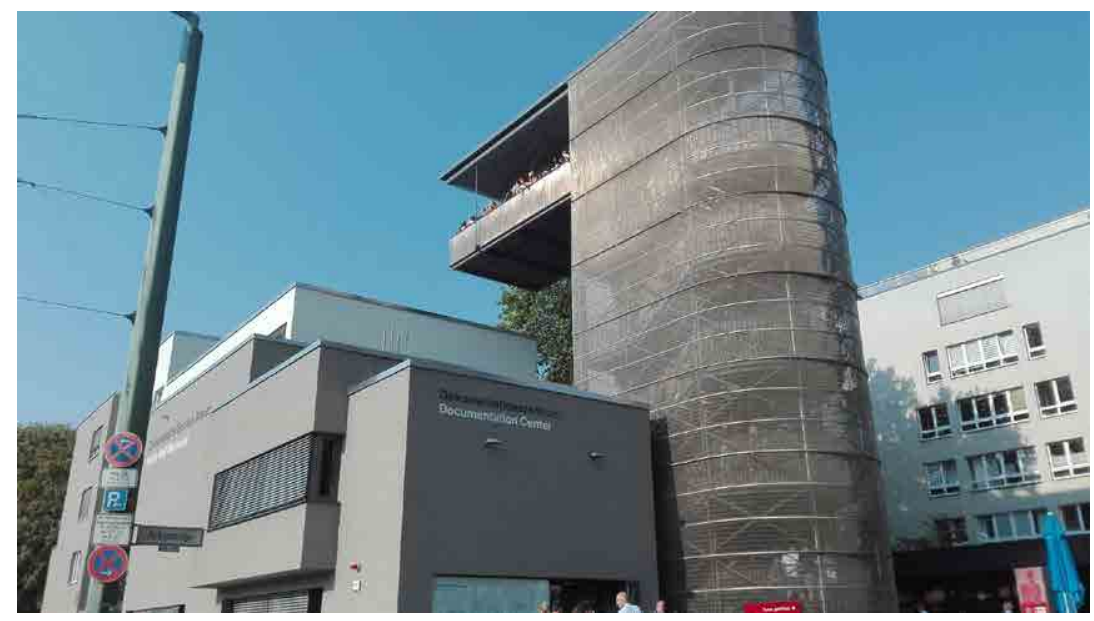

Imagen: Centro de Documentación del Memorial del Muro de Berlín.

Fuente: Foto tomada por el autor.

26 Axel Klausmaier (director de la Fundación Memorial del Muro de Berlín), entrevista por Jordi Guixé, 14 de marzo de 2016. Entrevista accesible en: «Citizen's voice.»

27 Klausmaier, entrevista. 


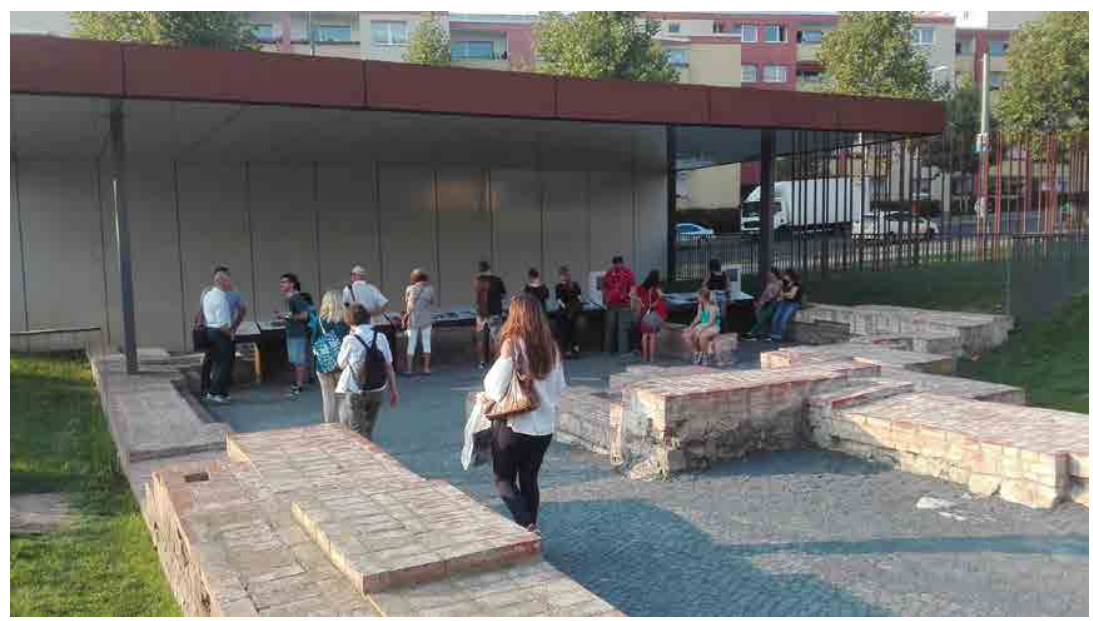

Imagen de la parte de la visita del Memorial del Muro de Berlín, recuperación de restos arqueológicos y espacio de información e interpretación, así como podemos ver una parte de reinterpretación en barrotes de hierro corten del propio muro.

Fuente: Foto tomada por el autor.

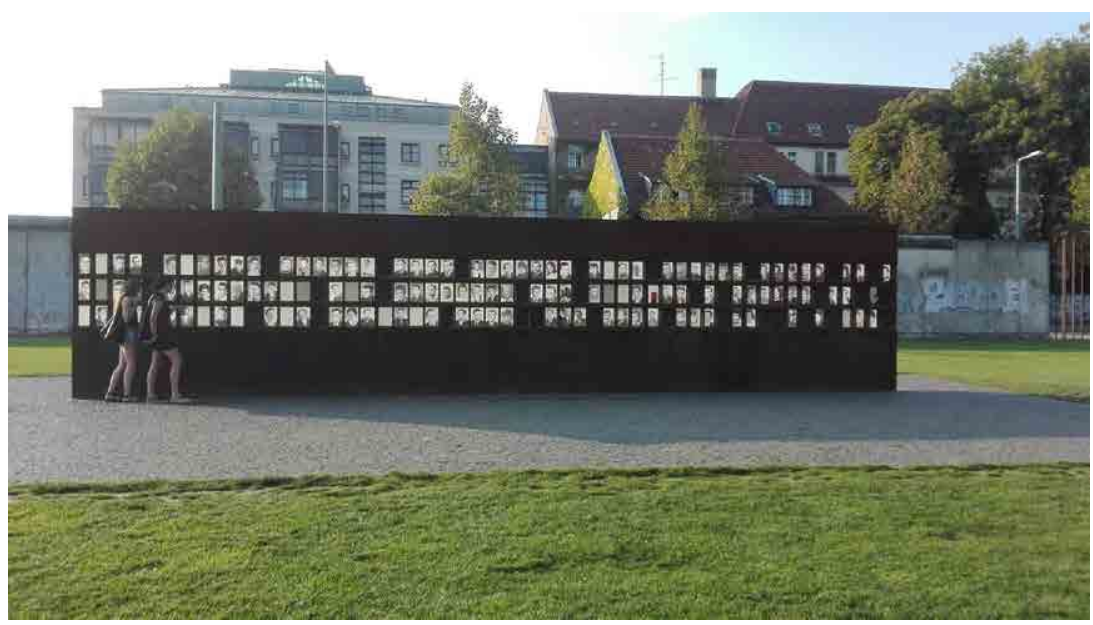

Imagen del espacio de interpretación del Memorial del Muro de Berlín dedicado a los testimonios y las víctimas.

Fuente: Foto tomada por el autor. 


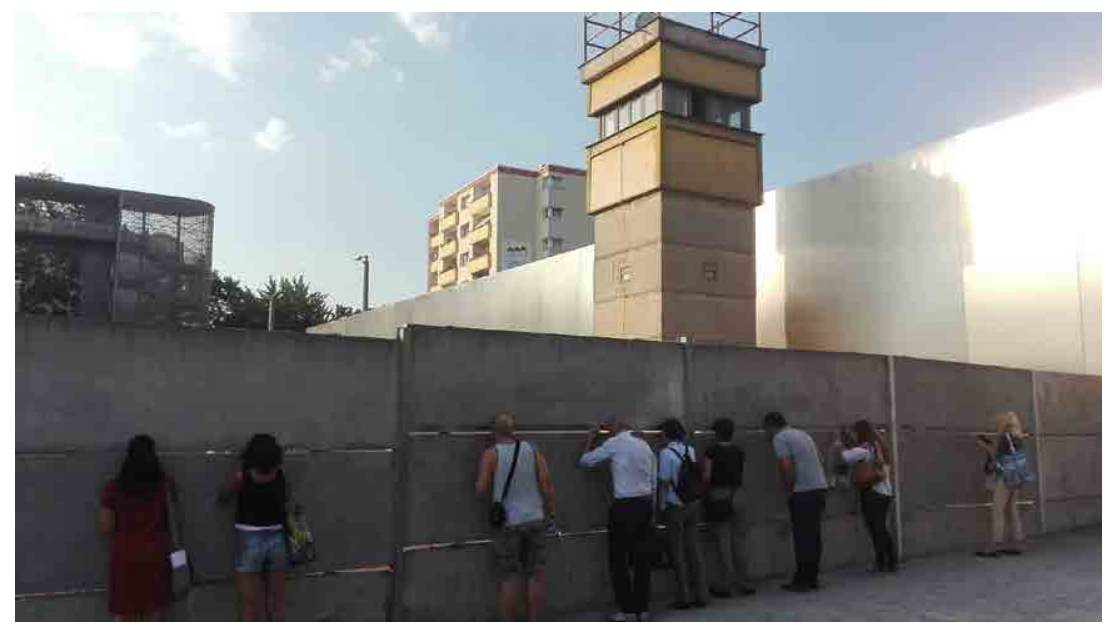

Imagen de la torre de vigilancia y espacios orginales del Memorial del Muro de Berlín. La amalgama de sistemas de reinterpretación y transmisión consiguen un aprendizaje positivo.

Fuente: Foto tomada por el autor.

La historia que nos cuenta el Muro de Berlín, es ahora más actual que nunca debido a las nuevas oleadas de exiliados y la construcción de nuevos muros en toda Europa y a lo largo de diferentes continentes. La perplejidad del presente nos condena a la estupidez negligente de no aprender de las lecciones del pasado, tanto en la esfera pública como política. El Memorial del Muro de Berlín es solicitado en los cinco continentes para trabajar sobre la memoria y los derechos humanos. Pero los acontecimientos marcan también el presente: en la red de espacios de memoria del Muro de Berlín se recupera y patrimonializa, el excampo de refugiados del muro: el Berlín Marienfelde Refugee Camp, que fue uno de los campos donde se amontonaban los refugiados del bloque del Este durante la guerra fría, y en los últimos años, se ha convertido, junto con el antiguo aeropuerto de Tempelfhoff y el excampo nazi de Dachau, uno de los campos para los refugiados políticos que huyen de la guerra de Siria en territorio alemán. La historia no es cíclica, los hechos nunca serán los mismos, pero vemos como las democracias a veces tanto olvidadizas, ahora recuperan espacios de internamiento y construyen nuevos muros, donde las recientes, no tanto 
lejanas, dictaduras genocidas ya habían recluido y reprimido personas humanas.

\section{Memoriales sobre la resistencia alemana}

Sobre los lugares de resistencia antifascista o antinazi, desde hace unos diez años ha habido una proliferación de espacios de recuerdo sobre ella. El relato de la larga exposición del memorial Gedensktätte Deutscher Widerstand (Memorial de la Resistencia Alemana) comienza con la República de Weimar y una impactante fotografía de las manifestaciones en Berlín, en junio de 1922, por el asesinato del ministro de asuntos exteriores; y finaliza, después de haber repasado todos los colectivos sociales resistentes (religiosos, étnicos, políticos, económicos, etc.), con una reflexión sobre dictadura y resistencia ${ }^{28}$. El edificio era un antiguo cuartel militar de la época. Ahora, convertido en un gran museo memorial y centro de documentación donde se estudia y se muestra la existencia, minoritaria pero efectiva de colectivos alemanes al nazismo.

En su gran patio de armas se recuerda y conmemora el atentado del 20 de julio de 1944 como resistencia militar del grupo Kreisau Kreis. Después de ser detenidos, los resistentes fueron ejecutados en la prisión de Plötzensee 1952 (Memorial de la Stauffenbergstrasse ${ }^{29}$ ) e inmortalizados en diversas películas tales como: Operación Valkyria, the Stauffenberg; Operation Valkyrie $^{30}$, Hooggeplaatste Duitse Officieren Beramen een aanslag op Adolf Hitler; y Operation Valkyrie, the Stauffenberg plot to kill Hitler ${ }^{31}$; entre otros filmes y documentales.

Igualmente, en la creación de nuevos espacios museísticos permanentes y concretamente sobre los lugares de resistencia debemos destacar el Museo de los Trabajadores de Otto Weidt (Museum Blindenwerkstatt Otto Weidt). Este pequeño museo

28 Peter Steinbach, Le Mémorial de la Résistance allemande (Berlín: Gedensktätte Deutscher Widerstand, 2004).

29 Monumento a la Resistencia Alemana.

30 Operación Valkyria es una película de 2008, dirigida por Bryan Singer.

31 Operation Valkyrie: The Stauffenberg Plot to Kill Hitler es un documental de 2008, dirigido por Jean-Pierre Isbouts. 
está relacionado con la red de museos sobre la resistencia alemana. De este lugar de memoria se destaca el origen de dicho museo memorial: una asociación de estudiantes recuperó el edificio original en el callejón, donde existió la antigua fábrica y talleres del propietario llamado Otto Weidt. Otto Weidt fue un empresario que empleó a trabajadores judíos, casi todos sordos o ciegos, con la excusa de que eran imprescindibles para el esfuerzo industrial de guerra. Sus talleres sirvieron para esconder a muchas personas de la represión y la persecución antisemita durante la guerra; sin embargo, al final, sus trabajadores fueron delatados, detenidos y deportados ${ }^{32}$. Esta pequeña fábrica fue el origen del proyecto como lugar de historia y memoria que esos estudiantes impulsaron. En 1989, se descubrió el taller de Otto Weidt y dicha asociación organizó una exposición temporal en una zona cercana a uno de los talleres antiguos, que, ante el éxito, se prolongó. No fue hasta el año 2006 cuando se convirtió en un espacio permanente. En la actualidad, encontramos una síntesis de la gente que ayudó a familias judías. Los judíos berlineses deportados fueron ciento sesenta mil, es decir, un $4 \%$ de la población. El museo es totalmente accesible -en cuanto a mobiliario y también lectura de textos- para personas discapacitadas y ciegas. Estuvo relacionado hasta 2006 con el Museo de los Judíos de Berlín, y posteriormente con el de la resistencia alemana (Deutsche Widerstand Museum), que lo gestiona actualmente. El número de visitantes es de tres mil mensuales, y la entrada e incluso los sistemas de auto guía son gratuitos ${ }^{33}$.

\section{Victimas y residentes: la acción social y artística}

Una de las personas que más se ha adentrado en el conocimiento y estudio de los monumentos en la ciudad

\footnotetext{
32 «History of the Museum,» MUSEUM Blindenwerkstatt Otto Weidt, https://www. museum-blindenwerkstatt.de/en/ausstellung/geschichte/.

33 Christel Trouvé (especialista en los espacios de memoria de Berlín y actual directora del Bunker Valentin Memorial en Bremen), entrevista por Jordi Guixé, 07 de mayo de 2011 y Kai Gruzdz (director del museo en 2014), entrevistado por Jordi Guixé, 07de mayo de 2011.
} 
de Berlín es Stefanie Endlich ${ }^{34}$. Endlich, en su libro sobre monumentos y memoriales en Berlín y Brandemburgo, describe las formas del recuerdo en el espacio público, pero con un interés destacado por la interactuación con los barrios, las personas, la ciudad. Su carrera profesional como comisaria de muchas obras y jurado en decenas de concursos públicos de memoria, la convierte en una gran especialista que nos ilumina sobre cómo la ciudad de Berlín se convierte en una práctica real de diálogo entre los memoriales, esculturas, monumentos y la ciudadanía.

Una de las acciones participativas más impactantes la encontramos en la obra del artista Horst Hoheisel; una obra de referencia del artista experto en desarrollar en sus trabajos el concepto de "contramonumentos», con los que busca la interpelación social más que el anclaje estético de las piezas. Por primera vez, delante de la Filarmonica de Berlín, donde se había hubicado la central nazi de operaciones secretas en Tiergartenstrasse número 4, Hoheisel junto con Andreas Knitz, crearon el proyecto del Autobús Gris ${ }^{35}$. Un autobús de hormigón gris armado, como pieza itinerante para recordar las deportaciones llamadas Aktion T4 (en referencia a la dirección de la sede central de operaciones) de los nazis en su voluntad de exterminar a los disminuidos psíquicos. Estfanie Endlich, amiga también de Hoheisel, fue además la presidenta del concurso sobre dicha escultura. A partir de la instalación del autobús Gris, que itinera por toda Europa como un memorial y monumento móvil, y despúes de casi diez años de acción de las asociaciones y de los artistas implicados, se inauguró en 2014 un memorial permanente sobre la deportación de disminuidos que completaba las instalaciones cercanas dedicadas a los colectivos de homosexuales, gitanos Sinti y Roma y a los Judíos exeterminados de Europa ${ }^{36}$.

34 Stefanie Endlich, Wege zur Erinnerung. Gedenkstätten und -orte für die Opfer des Nationalsozialismus in Berlin und Brandenburg (Berlín: Landeszentrale für pol. Bildungsarbeit, 2006). (trad. Cast.: Formas de recordar. Monumentos y lugares para las víctimas del nacionalsocialismo en Berlín y Brandenburgo).

35 La obra puede verse en: «Das Denkmal der grauen Busse,» Knitz.net, acceso el 06 de marzo de 2020, http://www.knitz.net/index.php?Itemid=3\&id=12\&option=com content\&task=view\&lang=pt-br.

36 Ver: Memorial and Information Point for the victims of National Socialist «Euthanasia,» Killings, acceso el 06 de marzo de 2020, https://www.t4-denkmal.de. 
Una característica de Berlín es la utilización del espacio público urbano para la resignificación permanente de hechos históricos, fruto del desarrollo de una política de memoria en el espacio público y de uso público. Así por ejemplo, desde la puerta de Brandenburgo hasta Alexanderplatz, siguiendo la avenida Unter den Linden, nos encontramos diferentes actuaciones. Especialmente cautivadora es la Biblioteca Vacía, situada en la Bebelplatz, ante la Universidad de Humboldt, realizada por Micha Ullman en 1995. Es una intervención artística dedicada a la memoria de quema pública de unos veinte mil libros el 10 de mayo de 1933, considerados por los nazis como obras literarias "anti alemanas» (allí se quemaron obras de Brecht, Einstein, Feuchtwanger, Freud, Gorki, Heine, Kafka, London, Mann, Marx, Voltaire, Zola etc.). El memorial está formado por una habitación subterránea con unas estanterías vacías, todo de color blanco neutro. Recuerda la ausencia de libros, la ausencia de cultura ${ }^{37}$. En las placas exteriores se recuerda la cita premonitoria de Heinrich Heine (1820): «Allí donde se queman los libros, se acaba por quemar personas».

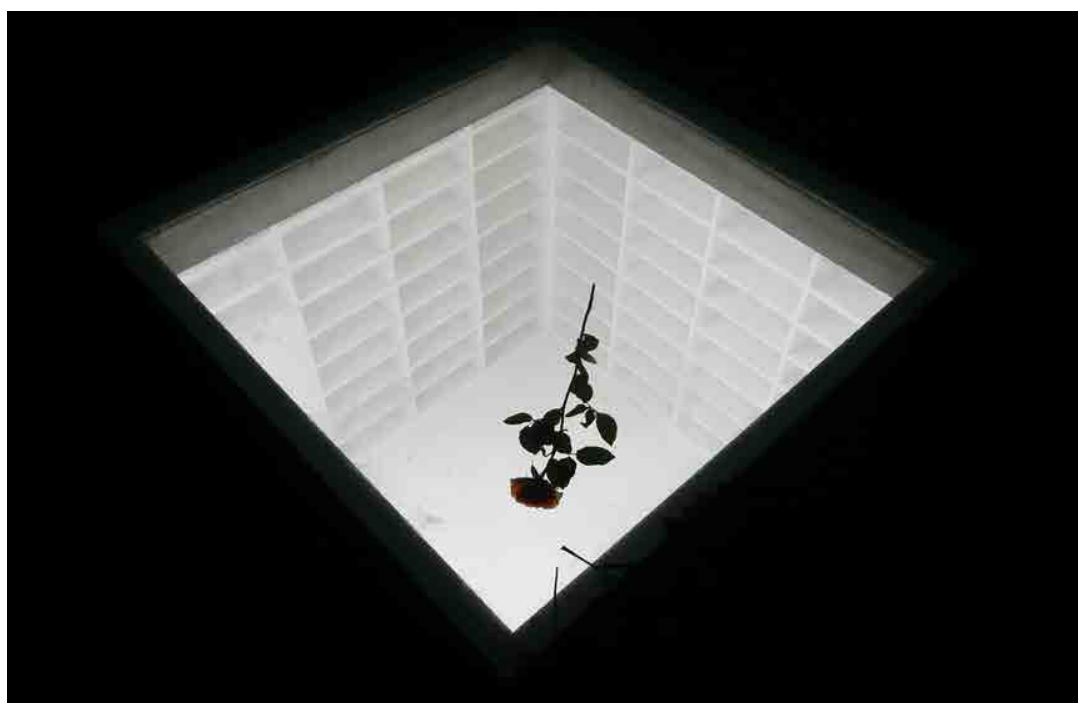

Imagen: Memorial de la Biblioteca Vacía de Micha Ullmann, Berlín. Fuente: Foto tomada por el autor.

37 «MICHA ULLAMAN,» JÜDICHES MUSEUM BERLIN, acceso en noviembre de 2020, https://www.jmberlin.de/en/topic-micha-ullman. 
$\mathrm{Al}$ otro lado de la calle, se encuentra la Neue Wache ('Nueva Guardia'). Edificio en forma de pequeño templo romano, fue construido inicialmente por Karl-Friedrich Schinkel en 1818. En 1920 fue remodelado por Heinrich Tessenow y transformado en monumento a la memoria de los caídos en la Primera Guerra Mundial. Durante la época nazi se reinterpretó su significado y se convirtió en el monumento a la gloria de los caídos heroicos alemanes. Y durante la época de la RDA, en 1958, se erigió un memorial a las víctimas del fascismo y del militarismo. Desde 1993, la Nueva Guardia es el memorial oficial de la República Federal Alemana dedicado a las víctimas de las guerras y la tiranía. Es criticado por su ecumenismo alrededor del sujeto víctima y a la inconcreción memorial dedicada a "todo tipo de víctimas» y por su utilización y manipulación política durante muchas décadas para acabar siendo una imagen con falta de concreción democrática y memorial que puede caer en el escepticismo.

Cerca de allí, hay diferentes obras de arte en el espacio urbano. Se trata de la obra La Casa Perdida -o casa vacía(The Missing House), intervención de Christian Boltanski que rememora una casa desaparecida durante la guerra en la que muchos de sus habitantes fueron deportados. El artista colocó varias placas en las paredes vacías donde vivían diferentes familias. La actuación impacta al visitante, el cual, sin necesidad de demasiadas explicaciones, se pregunta y se interpela sobre el destino del edificio y el destino de las familias que vivieron en ella.

También hay rastros de una interesante obra de arte urbana y memorial, Der Verlassene Raum de la plaza Koppen $^{38}$. Representa la ausencia del hogar por la deportación: monumento memorial del programa de 1938 en el barrio de Mitte. Esta escultura fue hecha en 1988, durante el 50 aniversario del pogromo judío de 1938, e incluye un poema en torno al espacio de la habitación como representación de

38 Endlich, Wege zur Erinnerung. Gedenkstätten und -orte für die Opfer des Nationalsozialismus in Berlin und Brandenburg. 
la ausencia y varias placas colocadas por asociaciones de deportados.

De todas formas, los espacios memoriales en Alemania no hay que verlos sólo como un proyecto de origen público, siempre asumido desde la gestión política. Muchas de las citadas iniciativas han surgido de la ciudadanía y ésta ha impulsado la mayoría de grandes y pequeños proyectos. Los actores sociales han seguido distintos y diversos motivos: movilización social, por iniciativa de colectivos de víctimas de represaliados, y, en muchos casos, emprendidos por compromisos artísticos personales o de otras iniciativas que interaccionan arte, acción y memoria en el espacio público.

Uno de estos ejemplos lo encontramos en el proyecto «Stolpersteine», del artista y creador Gunter Demnig, impulsado en Colonia en enero de 1995 sin la aprobación oficial del gobierno ni del ayuntamiento de la ciudad. Demnig ideó unas placas de cobre de 10 x $10 \mathrm{~cm}$, con la inscripción del nombre de víctimas detenidas y deportadas. Estas placas se iban colocando delante de las viviendas, ante centros de detención, en espacios relacionados con la memoria de la represión ${ }^{39}$. La financiación era voluntaria mediante donaciones particulares. A partir del año 2000, el proyecto se extendió a muchas otras ciudades y tomó la amplitud de monumento o memorial "descentralizado», llegando el año 2007 con más de 12.500 placas situadas en las calles y plazas de Alemania, Austria y Hungría, y ahora en 2019 el proyecto ha llegado a más de 24 países con una proliferación exponencial de placas, hablándose de más de sesenta mil placas colocadas ${ }^{40}$. Uno de los países que en el último año ha entrado muy potentemente en el proyecto es España donde incluso en zonas rurales y recónditas se ha dignificado la memoria de los deportados republicanos españoles a través

39 Visita de la El-De-Haus en Colonia, y entrevista con su director Wener Jung, Colonia, 2008.

40 Gunter Demnig, Stolperseteine, Gunter Demnig and his project (Colonia: The City of Cologne's Documentation Centre on National Socialism, 2007). 
de placas de Stolpersteine. Como apreciación global encuentro la iniciativa loable, pero no puedo dejar de aportar una valoración crítica, pues se plantea el dilema entre cantidad y calidad, en el proceso de la dignificación de ciertas biografías y de su reivindicación en el espacio público. La memoria de muchas de estas personas, hasta ahora ignorada, se presenta en el espacio público a través de un proyecto internacional y artístico. Mi pregunta es si eso es suficiente y también, si esta acción lo que hace es permitir el lavado de consciencia de muchas poblaciones que nunca se atrevieron a conmemorar la memoria del exilio, la república democrática y la deportación de sus conciudadanos.

De todas formas, podemos afirmar que Stolperteine es el proyecto más extenso sobre la marcación memorial en el espacio público. El mismo artista ya realizó un marcaje del recuerdo en el espacio público en un proyecto titulado «Roma und Sinti 1940», que consistió en marcar una línea de pintura blanca continua, con una máquina de pintar líneas medias en las carreteras, con los nombres grabados de las familias gitanas de Colonia deportadas en mayo de 1940, los Sinti y los Roma. Tanto la intervención de los Roma y Sinti como el «Stolpersteine» han configurado un espacio de memoria para recordar, pero, sobre todo, como afirma el historiador Werner Jung, por "confrontar la sociedad con su pasado [nazi]", para combatir el tópico y la ignorancia del «no sabíamos lo que estaba pasando» ${ }^{41}$. Una forma de resistencia efectiva y simbólica. La acción fue catalogada y reconocida oficialmente por el Gobierno alemán, pero es oportuno destacar los más de diez años de la construcción del proyecto artístico como proceso (1997-2007), lo que nos acerca a observar la lentitud de los procesos de memoria en países que teóricamente han sido pioneros y que han sido considerados de alta tradición memorial. Sobre las víctimas, sobre los resistentes, pero también sobre los perpetradores. 


\section{Trabajo en red}

El trabajo de memoria es un proceso, sacar conclusiones de ejemplos comparativos y de casos teóricos nos sirve -o nos debería servir-para aprender de la historia y de su transmisión memorial y aplicar nuevas fórmulas, más y mejor participadas en el presente por nuestros ciudadanos, implica seguir trabajando, actuando, investigando y activando procesos, profesionales, académicos y la sociedad en la construcción de la memoria colectiva. El reto es el mantener la tensión entre las diferentes escalas y dimensiones de las que hablaba al principio del texto.

El primer punto es poder reforzar en la transmisión del pasado en el presente, los proyectos y procesos culturales y garantizar su acceso a la ciudadanía como eje principal en la recuperación o resinificación de espacios de memoria. Solamente se han señalado algunos casos de memoriales o espacios de memoria alrededor del concepto de resistencia, nostalgia, víctima, patrimonio y turismo. La publicidad y el conocimiento también forma parte del trabajo sobre el pasado que debe ser interconectado transnacionalmente. Por ello, ya en la segunda década de este siglo, es necesario llevar a cabo diversas actuaciones para reforzar el conocimiento de los diferentes usos digitales sobre el pasado reciente en la esfera internacional. Los mapas de memoria, situándose en bases de datos de los espacios memoriales internacionales, son una herramienta que visualiza la importancia del trabajo memorial y unas bases de información digital, para obtener datos sobre instituciones memoriales de los cinco continentes.

Como segundo eje clave de activación memorial, la proliferación de redes, plataformas y agrupaciones de profesionales que promueven la memoria transnacional como un espacio de debate, de participación y también de gestión y promoción de proyectos memoriales comunes (International Coalition of Memorial Museums of Public Crimes-ICMEMO-, que está dentro del ICOM-UNESCO, la International Holacaust Remembrance Alliance, la International Coalition 
of Sites of consciens, la red Memorylab, el grupo de trabajo regional MEMORHA y nuestro más reciente Observatorio Europeo de Memorias, entre otros ${ }^{42}$.

La voluntad del Observatorio como red internacional es la de bordar sin complejos ni presiones $\mathrm{u}$ objetivos políticos, la complejidad temática a través de una red de memoria europea teniendo en cuenta y respetando la diversidad de memorias, cada una con sus particularidades (los grandes procesos tratados para el periodo 2011-2020 se pueden resumir en: la memorialización en el presente de las dos grandes dictaduras, nazismo y el estalinismo; la lucha por la democracia durante la dictadura franquista en España; las guerras civiles; los derechos civiles y ciudadanos, los movimientos pro democráticos en la Europa del Este durante la Guerra Fría; las dictaduras en Grecia y Portugal, los procesos dictatoriales y transicionales en países de América y de Europa, los conflictos relacionados con la descolonización del siglo XX, el tratamiento memorial en conflictos no resueltos o sobre la victimización o el terrorismo, entre muchos otros ${ }^{43}$.

Estas redes y plataformas son útiles también a la hora de analizar críticamente los procesos de memorialización y las políticas públicas de memoria a escala comparada e internacional. La memoria y sus retos en el siglo XXI debe ser forzosamente transnacional y comparada ${ }^{44}$.

42 Ver: International Holocaust Remembrance Alliance, acceso el 06 de marzo de 2020, https://www.holocaustremembrance.com; "directorio de comités,» ICOM Consejo internacional de Museos, acceso el 06 de marzo de 2020, http://icom.museum/ los-comites/comites-internacionales/comites-internacionales/comite-internacionalpara-museos-en-memoria-de-victimas-de-crimenes-publicos/L/1/; Sites of Conscience, acceso el 06 de marzo de 2020, http://www.sitesofconscience.org/es/; Memory Lab, acceso el 06 de marzo de 2020, http://memorylab-europe.eu; Réseau Memorha, acceso el 06 de marzo de 2020, http://www.reseaumemorha.org.

43 Véase: Portal web del Observatorio Europeo de Memorias, acceso el 06 de marzo de 2020, http://europeanmemories.net.

44 Aline Sierp y Jenny Wüstenberg. "Linking the Local and theTransnational: Rethinking Memory Politics in Europe,» Journal of Contemporary European Studies, $\mathrm{n}^{\circ} 23$ (2015): 321-329, DOI: https://doi.org/10.1080/14782804.2015.1058244. 


\section{Punto y seguido}

Más que conclusiones apunto unas ideas a modo de punto y seguido, pues el trabajo de memoria lo interpreto como un proceso permanente. Este trabajo debe ser como acabo de citar, analizado con otros procesos memoriales -lejanos o cercanospero comparativamente enriquecedores. Estas son las claves de desarrollar la permanente acción e interacción entre memoria y ciudadanía. Algunos de los espacios de memoria citados y analizados así como su interacción con redes internacionales de memoria son en sí mismos, la combinación de una memoria abierta -como proceso- y una interacción internacional.

En conclusión, en todos los Estados y procesos políticos, con o sin conflictos inherentes, encontramos ejemplos sobre la multiplicidad de memorias y procesos de memorialización permanente. Estas, configuran nuestra realidad democrática actual y el mapa sociopolítico de la Europa del presente. El mismo concepto de Europa es una yuxtaposición y multiplicidad memorial construida día a día. Esta riqueza, puesta en comparación con procesos paralelos (también con otros continentes) nos permite afirmar que la diversidad memorial debería marcar las políticas públicas de memoria a escala transnacional. Sin ignorar, ni olvidar el gran peso de las consecuencias del nazismo y el estalinismo en términos de construcción de relatos democráticos, otros procesos como las luchas contra los fascismos, las dictaduras, los derechos civiles, los procesos de paz y justicia, los movimientos democráticos contra regímenes autocráticos, las resistencias y las luchas por las libertades, también han engendrado unos valores transformadores que no pueden ser categorizados en un segundo nivel. Las historias nacionales, siempre están mucho más conectadas de lo que uno se piensa, pero aceptar y trabajar desde la multiplicidad y la diversidad nos evitaría entrar en el juego de la competencia memorial y, por tanto, la competencia sobre el sujeto víctima.

Es difícil, o bien imposible hacerlo sin una perspectiva totalmente multidisciplinar y haciendo un hincapié principal 
en cómo todas estas temáticas del pasado se transmiten y nos visitan en el presente. Por ello los lugares y espacios de memoria de las resistencias, de represión, las memorias invisibles o insumisas son los proyectos protagonistas de nuestros trabajos. Todo tipo de especialidades académicas se activan en el momento de recuperar, repensar y proyectar un lugar o un espacio de memoria (arte, arquitectura, antropología, sociología, ciencia política, trabajo con nuevas tecnologías, etc...). Hemos visto cómo también diferentes colectivos sociales se implican en ello y cómo, depende de cada país, lugar, región o ciudad, el poder, el Estado, sea cual fuere, prescinde o no de un relato abierto sobre el pasado.

Algunos proyectos están consolidados, otros solamente a modo de acompañamiento, presentan retos de futuro y de socialización y algunos proyectos en curso se deben a las mareas políticas para garantizar su futuro y otros son todavía ideas en proceso. He pretendido en este texto presentar capas y niveles diversos de acción, activación sobre la memoria y en su transmisión o patrimonialización, como modelos y también a modo de reflexión sobre resistencias y conflictos no solo en los lugares de memoria, sino también y todavía más en los procesos de resignificación de estos lugares.

Hemos recogido las experiencias de algunos de estos lugares y hemos dejado una puerta abierta al análisis de otros muchos casos citados en el texto. La activación de los lugares de residencia y resistencia se debe pues a las coyunturas sociopolíticas que las envuelven. Generalmente las sociedades sabias son luchadoras y tozudas, algunos de los proyectos presentados han necesitado de una negociación colectiva permanente y de una lucha como hemos dicho, tozuda y constante. Pero el acompañamiento del poder-Estado, región, ciudad-, si bien no es imprescindible si que deviene necesario en dos niveles: como aportación a toda política pública y como responsabilidad pública hacia los traumas o procesos del pasado.

Estos procesos de creación de lugares de memoria permiten, en los últimos años, crear una trama de especial 
significación en el marco de lo que llamamos patrimonio memorial. Un concepto que se vincula a la protección cultural pero también al turismo cultural. Hemos visto ejemplos en el hospital de Franja en Eslovenia, también los recorridos urbanos de Berlín y en su casi saturación de monumentos, instalaciones, esculturas de memoria que también forman parte del tejido cultural y turístico de la ciudad. Piensen que el incremento exponencial de visitantes tanto en el Memorial del Muro de Berlín como de la Topografía del Terror, ha llegado casi a saturar estas nuevas instalaciones (más de un millón en la Topografía en 2019). Estas cifras enormes (comparemos Auschwitz con más de dos millones) ${ }^{45}$ se deben al auge, aumento y consideración de estos lugares como patrimonio cultural y turístico. A modo de referencia, otro gran espacio de memoria internacional se quiere sumar a ser declarado Patrimonio de la humanidad y recientemente -noviembre de 2020- ha presentado su candidatura a la UNESCO ${ }^{46}$. Un ejemplo más de la defensa que hacía en el primer capítulo dicho texto.

Sobre la madeja italiana, podemos comparar procesos análogos en algunos países que como en España, cuesta «invertir» y elaborar el deber de memoria en referencia a la recuperación y dignificación de lugares. Pero al confrontar los procesos italianos, sobretodo el caso de Predappio está a día de hoy envuelto en una constante polémica sobre la conveniencia o no de promover un lugar de memoria en el marco de tanta nostálgia fascista y todavía no ve el futuro claro. A pesar de las asociaciones y el Estado y expertos, el ayuntamiento de Predappio cambió de color político y ha parado el proyecto de golpe. Los interrogantes persisten. Los retos son infinitos, pero claro que la vocación de dichos lugares que «resisten» implican procesos de comunicación, difusión y visita pedagógica y cultural permanente. Esas son las articulaciones comunes que hemos podido observar.

45 Entrevistas con Axel Klausmaier del memorial del Muro de Berlín, noviembre de 2012; Thomas Lutz, Topografía del Terror de Berlín, noviembre de 2012 y Piotr Cywinski, del Memorial de Auschwitz, octubre de 2017.

46 Invitación a la Presentación de la candidatura del Museo Sitio ESMA a la Lista de Patrimonio Mundial de la UNESCO. Reunión Zoom, 11 de noviembre de 2020. 
Por otra parte, y para dejar una conclusión más abierta, la multiplicidad memorial, sus efectos dinámicos, mobiles, polihédricos, nos acercan a una realidad cada vez más cercana al presente gracias a los métodos de transmisión contemporáneos, a la sociabilización y también, como no, gracias al trabajo con colectivos que poco a poco se van integrando en los relatos y narrativas que observamos de estos espacios memoriales. La memoria de resistentes y residentes comparten respresentación con la memoria de las víctimas, de los culpables o represores en muchos ya discursos públicos. De ahí la gran riqueza y potencial presente y futuro de los lugares que han resistido y se han convertido en residentes de unas memorias que se transmiten y se ejemplifican a través de ellos. Y si bien hemos observado una cierta asimetría en el caso Europeo (como hemos presentado entre Italia y Alemania) el recorrido ha sido y será enriquecedor para nuestras -a veces débiles sociedades democráticas- pero vale la pena recorrerlo y, como dijo el poeta: «el camino se hace al andar».

\section{Bibliografía}

Antich, Xavier. «Berlín, capital del duelo». Culturas [suplemento de La Vanguardia], Barcelona, 29 de junio de 2005.

Demnig, Gunter. Stolperseteine, Gunter Demnig and his project. Colonia: The City of Cologne's Documentation Centre on National Socialism, 2007.

Endlich, Stefanie. Wege zur Erinnerung. Gedenkstätten und -orte für die Opfer des Nationalsozialismus in Berlin und Brandenburg. Berlín: Landeszentrale für pol. Bildungsarbeit, 2006. (trad. cast.: Formas de recordar. Monumentos y lugares para las víctimas del nacionalsocialismo en Berlín y Brandenburgo).

Flores, Marcello, y Carlo Giunchi. «Predappio and the memory of the dictatorship.» Observing Memories, $\mathrm{n}^{\circ} 3$ (2019): 22-27. https://europeanmemories.net/magazine/predappio-and-thememory-of-the-dictatorship/.

Gerz, Joachim. «La certitude et le role du temps.» Videoinstalación y performance presentada en Représenter l'Irreprésentable?, 2015. 
Hirsch, Marianne. "Mobilising Memory for Change.» Conferencia presentada en COST meeting, Budapest, Central European University, 2014.

Huyssen, Andreas. «Memoria cultural y derechos humanos.» Conferencia presentada en el Centro de Cultura Contemporánea de Barcelona, 2010.

En busca del futuro perdido. México DF: Fondo de Cultura económica, 2002.

Mir, Conxita, Josep Calvet, y Joan Sagués. «Historia, patrimonio y territorio: políticas públicas de memoria en el frente del Segre y la frontera pirenaica catalana.» Hispania Nova, $\mathrm{n}^{\circ} 6$ (2006): 1-25. http://hispanianova.rediris.es/6/dossier/6d009.pdf.

Norá, Pierre, dir. Les lieux de mémoire. vol. 3. París: Gallimard, 1984-1993.

Norá, Pierre. «Reasons for the current upsurge in memory.» Transit Europaische Revue, no 22 (2002). https://www.eurozine.com/ reasons-for-the-current-upsurge-in-memory/.

Erramuzpé, Geneviève. «Informe sobre el proyecto de patrimonio y lugares de memoria comparados entre los países de Francia, Italia, Alemania.» Conferencia presentada en Berlín, Red MEMORHA, 2007.

Paticchia, Vito. Guerra e Resistenza sulla la linea Gotica Tra Modena e Bologna, 1943-1945. Modena: Edizioni Artestampa, 2006.

Sierp, Aline, y Jenny Wüstenberg. "Linking the Local and theTransnational: Rethinking Memory Politics in Europe.» Journal of Contemporary European Studies, $n^{\circ} 23$ (2015): 321329. DOI: https://doi.org/10.1080/14782804.2015.1058244.

Serrano, Miquel, y Maximiliano Fuentes. "Seminaire d'étude en Allemagne, Histoire, mémoire, transmission. Lieux d'Histoire et de Mémoire: Berlin-Ravensbrück.» Seminario de 10-16 de diciembre de 2007. Inedito.

Steinbach, Peter. Le Mémorial de la Résistance allemande. Berlín: Gedensktätte Deutscher Widerstand, 2004. 
Urbain, Jean-Didier. «Tourisme de mémoire, un travail de deuil positif.» Espaces, nº 80 (2003).

Vinyes, Ricard. «Informe sobre les polítiques públiques de reparació i memòria a Argentina i Xile. Una aproximació comparativa.» Informe inédito presentado en Barcelona, Dirección General de Memoria Democrática,2006.

VV.AA. «Cahier Tourisme de Mémoire.» Espace, nº 313 (2013): 3-96. . «Dossier: Le Tourisme de Mémoire.» Ancrage, (2008).

\section{Sitios Web}

Centre d'Etudis Lacetans. "Història.» Acceso en octubre de 2020. http://lacetans.solsonae.cat/seccions/historia.

European Observatory on Memories. "Citizen's voice.» Acceso el 06 de marzo de 2020. https://europeanmemories.net/videocategory/citizens-voice/.

ICOM Consejo internacional de Museos, "directorio de comités.» Acceso el 06 de marzo de 2020. http://icom.museum/loscomites/comites-internacionales/comites-internacionales/ comite-internacional-para-museos-en-memoria-de-victimasde-crimenes-publicos/L/1/.

ICMEMO. «Icmemo annual conference.» Acceso el 06 de marzo de 2020. http://icmemo.mini.icom.museum/wp-content/uploads/ sites/17/2019/01/Report_ICMEMO_Conference_2016_Milan. pdf.

ICMEMO Annual Conference, paper. «Kirsten John-Stucke "Wewelsburg Castle - an attraction pole of Dark Tourism How to deal with this phenomenon at a memorial site", 5th July 2016-.» Acceso en noviembre de 2020. http://icmemo. mini.icom.museum/documents/papers/.

Idrija Municipal Museum. Acceso el 06 de marzo de 2020. https:// www.muzej-idrija-cerkno.si/en/.

International Holocaust Remembrance Alliance. Acceso el 06 de marzo de 2020. https://www.holocaustremembrance.com. 
JÜDICHES MUSEUM BERLIN. «MICHA ULLAMAN.» Acceso en noviembre de 2020. https://www.jmberlin.de/en/topic-michaullman.

Knitz.net. «Das Denkmal der grauen Busse.» Acceso el 06 de marzo de 2020. http://www.knitz.net/ in d e x.ph p ? I e m id $=3 \&$ id $=12 \&$ o p ti o $n=$ c o m _ content\&task=view\&lang=pt-br.

KreisMuseum Wewelsburg. Acceso el 06 de marzo de 2020. https:// www.wewelsburg.de/.

Maison d'Izieu. Acceso el 06 de marzo de 2020. https://www. memorializieu.eu.

Memorial and Information Point for the victims of National Socialist «Euthanasia» Killings. Acceso el 06 de marzo de 2020. https:// www.t4-denkmal.de.

Mémorial Du Mur De Berlin. «LA DEMOLITION DU MUR ET LES VESTIGES AUJOURDıHUI.» https://www.berliner-mauergedenkstaette.de/fr/la-demolition-du-mur-51.html.

Memory Lab. Acceso el 06 de marzo de 2020. http://memorylabeurope.eu.

MUSEUM Blindenwerkstatt Otto Weidt. «History of the Museum.» https://www.museum-blindenwerkstatt.de/en/ausstellung/ geschichte/.

Portal web del Observatorio Europeo de Memorias. Acceso el 06 de marzo de 2020. http://europeanmemories.net.

Red Federal de Sitios de Memoria de Argentina. Acceso el 06 de marzo de 2020. https://www.argentina.gob.ar/ archivonacionaldelamemoria/direccionsitios.

Réseau Memorha. Acceso el 06 de marzo de 2020. http://www. reseaumemorha.org.

Sites of Conscience. Acceso el 06 de marzo de 2020. http://www. sitesofconscience.org/es/. 


\section{Fuentes primarias}

\section{Entrevistas}

Frassineti, Giorgio. Entrevista por Jordi Guixé. 26 de mayo de 2015.

Gruzdz, Kai. Entrevistado por Jordi Guixé. 07 de mayo de 2011.

Klausmaier, Axel. Entrevista por Jordi Guixé. 14 de marzo de 2016.

Trouvé, Christel. Entrevista por Jordi Guixé. 07 de mayo de 2011.

Weick, Pierre. Entrevista por Jordi Guixé. Noviembre de 2006. 2020 ,

\section{Citar este artículo}

Guixé Corominas, Jordi. "Lugares de resistencia y memoria: residir y resistir.» Historia Y MEMORIA, n 22 (2021): 199-244. DOI: https:/doi.org/10.19053/20275137.n22.2021.9875. 